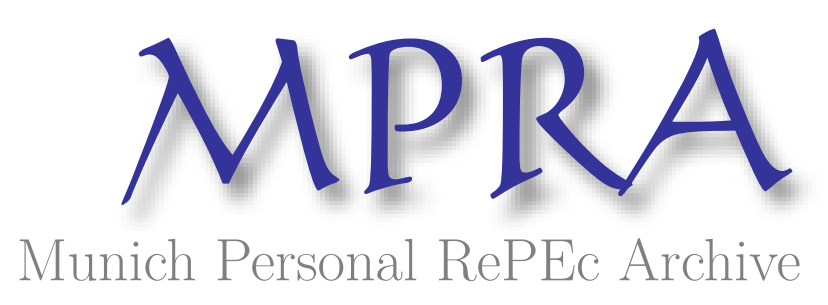

\title{
Mozambique Energy Outlook, 2015-2030. Data, scenarios and policy implications
}

Mahumane, Gilberto and Mulder, Peter

VU University Amsterdam

May 2015

Online at https://mpra.ub.uni-muenchen.de/65968/

MPRA Paper No. 65968, posted 06 Aug 2015 14:25 UTC 
Mozambique Energy Outlook, 2015-2030. Data, Scenarios and Policy Implications

Research Memorandum 2015-7

Gilberto Mahumane Peter Mulder

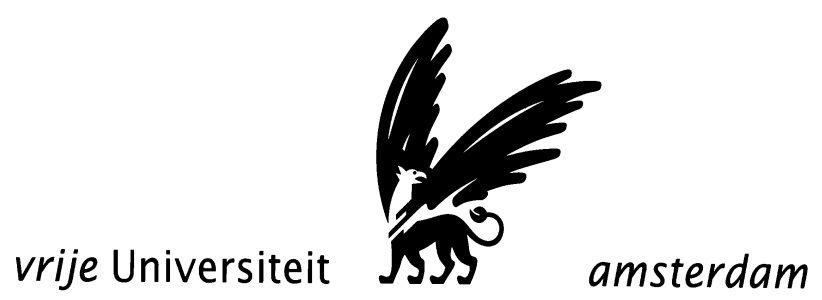




\title{
Mozambique Energy Outlook, 2015-2030. Data, Scenarios and Policy Implications
}

\section{Gilberto Mahumane $^{\mathrm{a}}$ and Peter Mulder ${ }^{\mathrm{b}}$}

\author{
${ }^{a}$ Eduardo Mondlane University, Maputo, Mozambique \\ \& VU University, Amsterdam, The Netherlands \\ Email: gilberto.mahumane@gmail.com \\ ${ }^{b}$ VU University, Amsterdam, The Netherlands
}

\begin{abstract}
This paper presents the first comprehensive Energy Outlook for Mozambique, a country that since long is one of the poorest nations of the world but since recently also developing into a leading energy producer. We present projections until 2030, based on a newly developed integrated long-run scenario model, new national and regional energy statistics, demographic and urbanization trends as well as cross-country based GDP elasticities for biomass consumption, sector structure and vehicle ownership. Our analysis shows an emerging 'energy-dichotomy' in Mozambique. On the one hand, the energy sector is characterized by a rapid and huge expansion. Until 2030, exploitation of the country's reserves of coal, natural gas and hydropower is likely to increase primary energy production at least six-fold and probably much more, most of which is destined for export. We show that, as a result, Mozambique is rapidly developing into an important player at international energy markets; it may well become one of the leading global producers of natural gas and coal. On the other hand, our analysis shows that households continue to account for the major part of total energy consumption, with the majority of the population still being deprived from access to modern energy fuels by 2030 . Hence, despite the spectacular rise of the extractive industry sector, population growth continues to be a key driver of energy consumption growth in Mozambique. Finally, we discuss the major challenges these findings pose for energy policy in Mozambique.
\end{abstract}

Keywords:

Mozambique, Energy Outlook, Energy Scenarios, Energy Policy 


\section{Introduction}

Over the last years Mozambique's natural resource wealth has attracted substantial foreign direct investments in large energy-intensive industries as well as in the mining, exploration and transformation sectors. This undoubtedly will have a large impact on Mozambique's role in international energy markets. In its latest Africa Energy Outlook, the IEA refers to Mozambique as an emerging large energy producer that is expected to soon join the group of leading energy producers in Africa, together with Nigeria, South Africa and Angola (IEA 2014). This is a sharp break with the recent past: for many decades the Mozambican energy sector was characterized by decline, disruption and post-war reconstruction, despite its abundant natural resources. Against this background we present in this paper a comprehensive Energy Outlook for Mozambique until 2030, based on a newly developed integrated long-run scenario model of the Mozambican energy sector (Mahumane and Mulder 2015). To the best of our knowledge, our analysis is the first integrated Energy Outlook for Mozambique in the energy studies literature.

Until recently, the Mozambican energy sector is probably best known for the Cahora Bassa dam (HCB), which is, with 2075 MW of capacity, one of the largest hydropower installations in Africa. However, Mozambique has the potential to build another 5000 MW of hydropower. In addition, the country has large sedimentary basins of natural gas: on-shore reserves have been discovered and off-shore areas in the Rovuma basin are now researched and could contain more than 100 trillion cubic feet of gas, and probably also oil. Until now, commercial discoveries are limited to natural gas whereas oil discoveries appear to be economically not yet viable - but the area clearly has a potential for oil, and exploration is in the early phase. In addition, during the last decade massive deposits of coal in the northern province of Tete have been (re-)discovered, with an estimated size of about 23 billion tons. ${ }^{1}$ Moreover, the country has vast extractable reserves of mineral sands, containing, among others, ilmenite, zircon, rutile and titanium slag. Finally, the country's has a great biomass and biofuels potential, with estimates of at least 30 million hectares of arable land currently unused.

Paradoxically, despite all this wealth, the Mozambican population so far is heavily reliant on traditional forms of energy: about $97 \%$ of total household energy needs are still met by traditional biomass fuels such as wood and charcoal, only about $20 \%$ households have access to electricity and LPG consumption is limited to better-off households in a few major cities. Also, the country ranks 10th from bottom on the Human Development Index, about $80 \%$ of its population lives on less than \$2 (PPP) a day and per capita GDP is only about $\$ 1000$ (PPP). At the same time, this situation is gradually changing for the better. For example, over the last decade and a half Mozambique experienced rapid economic growth, the urban population grew with about $50 \%$ since 2000 , electricity access doubled over the last seven years and car ownership more than doubled since 2000.

\footnotetext{
${ }^{1}$ Back in the 1850s Richard Thornton, a geologist on the Zambezi expedition under David Livingstone, was the first to undertake geological research into Tete's coal occurrence (Hatton and Fardell, 2012).
} 
Our analysis fits in the tradition of studies presenting country-specific energy outlooks (see, for example, Aburas 1993, Bhattacharyya 2010, Kibune and Kudo 1996, Kim et al. 2001, McPherson and Karney 2014, Pereira Jr. et al. 2008, Solomon and Krishna 2011, Yamashita and Ishida 2000, Zachariadis 2011, Zhou et al. 2013). The integrated Energy Outlook for Mozambique presented in this paper starts from historical trends since 2000 and subsequently covers the anticipated surge in natural resources exploration until 2030, exploring the potential impact of this surge on energy supply and demand, the energy infrastructure and economic growth in Mozambique. Our scenario analysis is driven by newly developed and locally collected energy statistics for the recent past as well as information about the latest developments and future plans as regards the production and transformation of energy in Mozambique. These data are supplemented with demographic and urbanization trends as well as cross-country based GDP elasticities with respect to biomass consumption, sector structure and vehicle ownership. The analysis makes use of LEAP, the Long range Energy Alternatives Planning System - an integrated modeling tool that can be used to track energy consumption, production and resource extraction in all sectors of an economy (Heaps, 2012). We model energy demand by households, transport and extractive industries, as well as the sectors agriculture, manufacturing, services, government and other. Also we specify electricity demand from neighboring countries in the region, given their essential role in developing the Mozambican electricity market. As regards the supply side, we model electricity production on a project by project basis, as well as gas exploration, coal mining, mineral (heavy) sands mining and charcoal production.

In doing so, we offer, in contrast to other studies, the first comprehensive Energy Outlook study for Mozambique as an emerging leading energy producer. In an unpublished ministerial report, Mulder (2007) presented a rudimentary first version of a long-term integrated energy scenario study for Mozambique, based on data for the period 2000-2005. But most of the existing (consultancy) planning studies for Mozambique typically consider one dimension or subsector of the energy system, like for example the electricity sector (Ministry of Energy /Norconsult 2009, Norconsult, 2011). In their review of the energy situation in Mozambique, Cuvilas et al. (2009) provide basic statistics for the period 2000-2006 as well as an assessment of future energy supply potential. Bucuane and Mulder (2009b) estimate the potential resource wealth of Mozambique in comparison to other countries, with the aim to evaluate whether the foreseen exploration of natural resources in Mozambique will pose a threat rather than a blessing to its economic development. Sebitosi and Da Graça (2009) examine the potential of Tete province to develop into a regional industrial hub for the Southern African region, given its natural resource wealth in general and the presence of HCB in particular. Others have studied Mozambique for its traditional biomass and biofuels markets (Arndt et al. 2010; 2011, Batidzirai et al. 2006, Brouwer and Falcão 2004, Di Lucia 2010, Schut et al. 2010, Schut et al. 2014), electricity sector reform (Nhete 2007), drivers and barriers to rural electrification (Ahlborg and Hammar 2014, Mulder and Tembe 2008) and the 
micro-economics of residential energy consumption (Arthur et al. 2010, 2012).

The structure of the paper is as follows. In section 2 we provide information on the database underlying our scenario analysis. Section 3 portraits major developments in the Mozambican energy sector during the recent past, in order to put our Energy Outlook in context. In Section 4 and 5 we describe our scenario methodology and modelling framework, respectively. Section 6 and 7 present the Energy Outlook for Mozambique, respectively focusing on the energy supply and demand side. Section 8 concludes and discusses key policy implications.

\section{Data}

Our scenario analysis has its roots in (newly collected) historical data for the period 2000-2011, supplemented with information about future plans as regards the production and transformation of energy in Mozambique during the period 2012-2030 - our scenario timeframe. Most of the energy statistics for Mozambique that we use in our analysis were collected and processed by the Directorate of Studies and Planning (DEP) of the Mozambican Ministry of Energy (ME, 2012). ${ }^{2}$ Underlying data have been provided by a range of local institutions, including National Institute of Petroleum (INP), National Company of Hydrocarbons (ENH), Mozambique Petroleum Company (PETROMOC), Cahora Bassa Hydroelectric (HCB), Mozambique power utility (EdM), Mozambique Transmission Company (MOTRACO), National Energy trust-Fund (FUNAE), South African multinational gas and Oil company (SASOL), Matola Gas Company (MGC), Portuguese Petroleum and Gas Company (GALP), VidaGas, National Institute of Statistics (INE), Mozambique Petroleum Import (IMOPETRO) and the Ministry of Planning and Development (MPD). Historical data on consumption of traditional biomass have been estimated on the basis of combined information from national survey data published by INE and international data published by the IEA and FAO.

Data on existing and future production of mineral resources (coal, natural gas and heavy sands) were compiled on the basis of information gathered from the Ministry of Mineral Resources (MIREME), KPMG International (2013), United States Geological Survey (Yager, 2012) and the US Energy Information Administration (EIA/DOE). In addition we collected information from press releases by private companies (in Bloomberg, Reuters, Mining Weekly, Mozambique Information Agency-AIM, and other national press), as well as from personal communications with local experts. Information on future electricity trade in the region is based on information published in the Integrated Resource Plan by the South African government (SA Department of Energy, 2011) and interviews with local experts. Finally,

\footnotetext{
${ }^{2}$ This has been done within the EuropeAid /127640/SER/MZ project "Capacity Building in Energy Planning and Management in Mozambique". The authors of this article participated in this project.
} 
demographic and economic data on Mozambique were obtained from INE, the Ministry of Planning and Development and the Mozambique Central Bank (BM) as well as from the World Bank, the International Monetary Fund (IMF, 2013), the United Nations Department of Economic and Social Affairs (2011 Revision), and the African Development Bank (AfDB). All locally collected data, insofar possible, have been checked against data from international sources, including British Petroleum (BP Statistical Report 2012), International Energy Agency (IEA 2013a, 2014), United Nations Populations statistics and the World Development Indicators as published by the World Bank.

\section{The Energy sector 2000-2011}

In order to provide key insights into the context of our energy scenarios, we start this Energy Outlook with a brief description of the evolution of the Mozambican energy sector during the recent past (2000-2011; our pre-scenario period). We do so by presenting first, in Table 1 a short energy balance of the country.

First and foremost, the data presented in Table 1 show an already sizeable expansion of the energy sector, which is unprecedented in the history of the country. Since 2000, on average and by approximation, energy production increased annually with 6\%, imports with $10 \%$, exports with $20 \%$ and final consumption with $4 \%$. Second, this expansion is largely driven by developments in the natural gas and electricity markets (more on this below). Third, despite the emerging production and consumption of modern energy forms, energy services from traditional biomass (fuelwood and charcoal) still dominate the energy balance of Mozambique: in 2011 it accounted for 64\% of energy production and $77 \%$ of final energy consumption. As regards the latter, less than 5\% of households in Mozambique are using a modern form of energy for cooking at home, the remainder uses charcoal and wood fuel (INE, 2009; INE, 2010a). In rural areas, where the majority of the population lives, $97 \%$ of households rely on daily wood fetching for their energy needs. In urban areas charcoal has rapidly become the prevailing fuel of choice, accounting for approximately 50 per cent of all energy consumption expenditures.

The rise of the natural gas market in Mozambique started in 2004 with the mass exploitation of the Pande/Temane onshore gas fields, accomplished through a consortium led by the South African company SASOL. Most gas is exported to South Africa via a pipeline, signifying the largest inter-African gas trading project. Mozambique is entitled to a royalty of 5\% of the total exports, but so far natural gas consumption in Mozambique has been lower than the potential royalty gas it can take. 


\begin{tabular}{|c|c|c|c|}
\hline & \multicolumn{2}{|c|}{ ktoe } & \multirow{2}{*}{$\begin{array}{r}\text { Av. Ann. } \\
\text { Growth } \\
2000-11\end{array}$} \\
\hline & 2000 & 2011 & \\
\hline Production & 7,252 & 12,786 & $5.8 \%$ \\
\hline Biomass & 6,418 & 8,199 & $2.5 \%$ \\
\hline Electricity & 834 & 1,417 & $5.5 \%$ \\
\hline Hydro & 830 & 1,415 & $5.5 \%$ \\
\hline Other & 4 & 2 & $-6.8 \%$ \\
\hline Coal & 12 & 465 & $44.7 \%$ \\
\hline Natural gas & 1 & 3,126 & $125.2 \%$ \\
\hline Petroleum products & 0 & 44 & $131.4 \%$ \\
\hline Import & 657 & 1,684 & $9.9 \%$ \\
\hline Electricity & 112 & 737 & $20.8 \%$ \\
\hline Petroleum products & 546 & 947 & $5.7 \%$ \\
\hline Export & 670 & 4,009 & $19.6 \%$ \\
\hline Electricity & 670 & 1,028 & $4.4 \%$ \\
\hline Natural gas & 0 & 2,981 & $252.7 \%$ \\
\hline Primary Energy Supply & 7,240 & 10,460 & $3.7 \%$ \\
\hline Transformation (Gas to Electricity) & 0.75 & 7.27 & $25.5 \%$ \\
\hline Transformation (Fuelwood to Charcoal) & 1,472 & 1,705 & $1.5 \%$ \\
\hline Other* & 183 & 498 & $10.5 \%$ \\
\hline Final Consumption & 5,584 & 8,250 & $4.0 \%$ \\
\hline Biomass & 4,946 & 6,391 & $2.6 \%$ \\
\hline Electricity & 176 & 902 & $17.8 \%$ \\
\hline Natural gas & 0.18 & 81 & $84.2 \%$ \\
\hline Petroleum products & 463 & 875 & $6.6 \%$ \\
\hline
\end{tabular}

* International bunkers, change in reserves, own use, transmission and distribution losses, statistical differences. Sources: see section 2.

The electricity market in Mozambique is principally characterized by its $2075 \mathrm{MW}$ hydropower capacity, provided at the Cahorra Bassa dam (HCB) in the northwestern province of Tete. The country has another 200MW or so of power generation capacity installed, in the form of 3 small hydro dams, some natural gas turbines, and numerous diesel generators. $\mathrm{HCB}$ can generate more than enough for the entire country and beyond. In 2011, the national electricity company EdM - which has a near monopoly on electricity distribution in Mozambique - got 11 times more energy from HCB than it did on average during the 1990s, when it was largely dependent on imports for its supply (46\% over the 1990s). The latter is due to fact that HCBs electricity production was interrupted during the protracted post-independence civil war (1975-1990). After rehabilitation, HCB production regained its role by the end of the 1990s. In the period 2006-2011, HCB exported $76 \%$ of its production to South Africa, against $86 \%$ in the five years prior to 2006 - the rest being sold to EdM. Since 2000 Mozambique started re-importing electricity on a 
large scale from the South African power utility Eskom, in order to supply the newly constructed aluminum smelter Mozal in the south of Mozambique (see below) - accomplished via a separate distribution line managed by the company Motraco. It is considered that this is the same electricity sold by HCB to Eskom that the latter then re-exports to Mozambique, thus providing a wheeling service. This expensive solution is necessary in the absence of a domestic north-south transmission line to connect $\mathrm{HCB}$ to Motraco's system and EdM's grid in southern Mozambique.

In Table 2 we present a sectoral breakdown of domestic consumption of energy and electricity, in relation to the sector structure of the Mozambican economy (in terms of GDP). In short, from the Table it can be seen that the sector services accounts for about one-third of total GDP, followed by the sectors agriculture and fishing (about 25\%) and industry (15\%), while the transport and government sector each make up for about 10\%. In terms of energy consumption, the picture is completely different: in 2011 households were responsible for about $60 \%$ of total energy consumption, followed by the transport sector $(30 \%)$ and industry (8\%). Evidently, this dominance of the household sector illustrates the small size of the Mozambican economy. Table 2 also shows that during the period 2000-2011 energy consumption increased most rapidly in the Extractive Industry along with the Mozal aluminum smelter. By 2011 the extractive industry in Mozambique was still relatively small, and mainly consisting of the previously mentioned exploration of natural gas. However, in 2010 large-scale exploration of coal started in Tete province, leading to the first shipment of mineral coal for export in September 2011. In addition, improved infrastructure and economic development has led to a notable increase in energy consumption by the transport sector.

Table 2. Sector composition of GDP, final energy consumption and electricity consumption.

\begin{tabular}{|c|c|c|c|c|c|c|c|c|c|}
\hline & \multicolumn{3}{|c|}{ GDP } & \multicolumn{3}{|c|}{$\begin{array}{l}\text { Final energy } \\
\text { consumption }\end{array}$} & \multicolumn{3}{|c|}{ Electricity consumption } \\
\hline & $\%$ & $\%$ & Change & $\%$ & $\%$ & Change & $\%$ & $\%$ & Change \\
\hline & 2000 & 2011 & $2000-11$ & 2000 & 2011 & $2000-11$ & 2000 & 2011 & $2000-11$ \\
\hline Agriculture \& Fishing & 25.7 & 24.7 & $-4 \%$ & 0.3 & 0.3 & $0 \%$ & 0.0 & 0.0 & -- \\
\hline Extractive Industry & 0.5 & 1.3 & $160 \%$ & 0.0 & 0.3 & -- & 1.1 & 1.3 & $18 \%$ \\
\hline Other Industry \& Construction & 14.9 & 15.5 & $4 \%$ & 2.8 & 8.6 & $207 \%$ & 66.0 & 83.1 & $26 \%$ \\
\hline MOZAL aluminum smelter & 1.2 & 4.0 & $233 \%$ & 2.0 & 7.7 & $285 \%$ & 48.4 & 76.0 & $57 \%$ \\
\hline Other Industry \& Construction & 13.7 & 11.5 & $-16 \%$ & 0.8 & 0.8 & $0 \%$ & 17.6 & 7.1 & $-60 \%$ \\
\hline Services & 33.0 & 32.3 & $-2 \%$ & 0.4 & 0.4 & $0 \%$ & 9.0 & 3.8 & $-58 \%$ \\
\hline Transport & 10.3 & 11.6 & $13 \%$ & 6.4 & 31.2 & $388 \%$ & 0.0 & 0.0 & -- \\
\hline Electricity and Water & 4.5 & 4.8 & $7 \%$ & 0.2 & 0.1 & $-50 \%$ & 4.6 & 1.4 & $-70 \%$ \\
\hline Government & 11.2 & 9.8 & $-13 \%$ & 0.0 & 0.0 & $0 \%$ & 1.0 & 0.4 & $-60 \%$ \\
\hline Households & -- & -- & -- & 89.9 & 59.1 & $-34 \%$ & 18.3 & 9.9 & $-46 \%$ \\
\hline
\end{tabular}


In terms of electricity consumption, the picture changes again. Most notably is the vast dominance of the aluminum smelter Mozal, which in 2011 was responsible for about three quarters of total electricity consumption in the country. Clearly, this fact is a key feature of (future) energy planning and energy policy in Mozambique, as will be shown throughout the paper. In 2011, Other industry and services made up for, respectively, about $7 \%$ and $4 \%$ of total electricity consumption, while about $10 \%$ is consumed by households. Mozambique's electricity consumption had grown steadily with GDP from 2001-2006, with an average GDP elasticity of electricity consumption of nearly 1. However, since 2006, electricity consumption has grown 1,6 times faster than GDP, denoting an electricity-intensification of the economy. The strong growth came from all sectors. Reflecting the country's unequal economic development, until recently about two-third of the country's demand for electricity is concentrated in the southern region.

Although the share of the residential sector in total electricity consumption fell over time since 2000 , total electricity consumption by households increased considerably under influence of increasing (urban) welfare and (rural) electrification. In 2011, 107 out of 128 districts were connected to the main grid, with coverage limited to the district headquarters in many rural districts. Since 2000, the electrification rate grew on average with $15 \%$ per year, from $4 \%$ of households having electricity in 2000 to $18 \%$ in 2011. However, regional differences in access are considerable. In the Maputo area access to electricity is over $60 \%$, while in most other provinces access varies between $6 \%$ and $24 \%$. Cross-regional variation in access is nevertheless decreasing over time, due to intense efforts to electrify rural areas. In 2011 more than 163.000 households were connected to the main grid, which is a six-fold increase from 2000. Over the same period the number of clients of the national electricity company EdM grew with 400\%. Total electricity per capita almost tripled between 2000 and 2011; when we exclude electricity consumption by Mozal, this figure reduces to a still impressive growth of about $80 \%$. Consumption per EdM-client decreased over time because the electrification efforts implies increasingly connecting relatively poor people in peri-urban and rural areas, people who consume relatively small quantities. 


\section{Scenarios}

We chose to develop in this paper a limited number of scenarios that are intentionally fairly simple and straightforward. Our main goal is to highlight major trends in the transformation of the emerging Mozambican energy sector, including the expected consequences for both domestic and international energy markets. The development of richer scenarios, including more detail and variation in terms of energy policies, structure of energy demand, energy supply mix options and regional differences, is deliberately left for future work.

Energy outlooks usually give three basic scenarios - medium, high and low - that are often largely defined by GDP and population growth expectations. We follow this approach, but add a fourth scenario that assumes exploitation of Mozambique's natural resources exploration to its fullest potential. We label our three basic scenarios as Reference, Reference High and Reference Low; the fourth scenario is labelled Extractive. Reference is the most likely development path. It is to be noted that this is not a 'business as usual' scenario, but is based on baseline projections plus activities of new extractive industry and electricity generation projects that are (almost) sure to be realized, taking into account realistic and somewhat conservative estimates about the output price development in the extractive and aluminum industry. Furthermore, it adopts a medium variant of population growth scenarios, a modest decline in household size, a moderate speed of urbanization and somewhat conservative estimates as regards the development of energy intensity improvements across sectors. Reference High and Reference Low then refer, respectively, to the optimistic and pessimistic variant of Reference - thus assuming higher (lower) baseline economic growth, lower (higher) population growth, higher (lower) speed of urbanization, faster (slower) decline of household size and energy intensities across sectors and higher (lower) output price developments in the extractive and aluminum industry. Finally, our Extractive scenario describes the expected evolution of the Mozambican energy system if all potential projects of extractive and aluminum industries as well as power generation are realized, including those projects that are yet (very) uncertain. Because of this focus, we assume in this scenario all other leading dimensions of the model to be equal to the Reference or Reference High scenario. We refer to Table 3 for a brief summary and overview or scenarios. 
Table 3. Scenarios

\begin{tabular}{|c|c|c|c|c|c|c|c|c|c|}
\hline Scenario & Variant & Description & $\begin{array}{l}\text { Annual } \\
\text { growth } \\
\text { Baseline } \\
\text { GDP* }\end{array}$ & $\begin{array}{l}\text { New projects } \\
\text { extractive } \\
\text { industry and } \\
\text { power sector }\end{array}$ & $\begin{array}{l}\text { Output price } \\
\text { extractive } \\
\text { and } \\
\text { aluminum } \\
\text { industry } \\
\end{array}$ & $\begin{array}{l}\text { Population } \\
\text { growth }\end{array}$ & $\begin{array}{l}\text { Household } \\
\text { size }\end{array}$ & $\begin{array}{l}\text { Speed of } \\
\text { urbanization }\end{array}$ & $\begin{array}{l}\text { Energy } \\
\text { intensity } \\
\text { improvement } \\
\mathrm{s}\end{array}$ \\
\hline \multirow{3}{*}{ Reference } & Medium & $\begin{array}{l}\text { The most likely } \\
\text { development } \\
\text { path. }\end{array}$ & $\begin{array}{l}\text { Gradual } \\
\text { decrease to } \\
4.7 \% \text { in } \\
2030 .\end{array}$ & $\begin{array}{l}\text { Including } \\
\text { those that are } \\
\text { (almost) sure } \\
\text { to be realized }\end{array}$ & $\begin{array}{l}\text { Realistic and } \\
\text { somewhat } \\
\text { conservative } \\
\text { estimates }\end{array}$ & $\begin{array}{l}\text { Medium } \\
\text { growth } \\
\text { scenario }\end{array}$ & $\begin{array}{l}\text { Linear } \\
\text { extrapolation } \\
\text { of decreasing } \\
\text { trend }\end{array}$ & $\begin{array}{l}\text { Medium } \\
\text { scenario }\end{array}$ & $\begin{array}{l}\text { Realistic and } \\
\text { somewhat } \\
\text { conservative } \\
\text { estimates }\end{array}$ \\
\hline & Low & $\begin{array}{l}\text { The pessimistic } \\
\text { variant of } \\
\text { Reference- } \\
\text { medium. }\end{array}$ & $\begin{array}{l}\text { Gradual } \\
\text { decrease to } \\
3.8 \% \text { in } \\
2030 .\end{array}$ & $\begin{array}{l}\text { Same as } \\
\text { Reference- } \\
\text { medium }\end{array}$ & $\begin{array}{l}\text { Low } \\
\text { estimates }\end{array}$ & $\begin{array}{l}\text { High growth } \\
\text { scenario }\end{array}$ & $\begin{array}{l}\text { Trend } 50 \% \\
\text { slower than } \\
\text { Reference- } \\
\text { medium }\end{array}$ & $\begin{array}{l}\text { Trend } 50 \% \\
\text { slower than } \\
\text { Reference- } \\
\text { medium }\end{array}$ & $\begin{array}{l}\text { Same as } \\
\text { Reference- } \\
\text { medium }\end{array}$ \\
\hline & High & $\begin{array}{l}\text { The optimistic } \\
\text { variant of } \\
\text { Reference- } \\
\text { medium. }\end{array}$ & $\begin{array}{l}\text { Gradual } \\
\text { decrease to } \\
5.9 \% \text { in } \\
2030 .\end{array}$ & $\begin{array}{l}\text { Same as } \\
\text { Reference- } \\
\text { medium }\end{array}$ & $\begin{array}{l}\text { High } \\
\text { estimates }\end{array}$ & $\begin{array}{l}\text { Low growth } \\
\text { scenario }\end{array}$ & $\begin{array}{l}\text { Trend } 50 \% \\
\text { faster than } \\
\text { Reference- } \\
\text { medium }\end{array}$ & $\begin{array}{l}\text { Trend } 50 \% \\
\text { faster than } \\
\text { Reference- } \\
\text { medium }\end{array}$ & $\begin{array}{l}\text { Same as } \\
\text { Reference- } \\
\text { medium }\end{array}$ \\
\hline Extractive & & $\begin{array}{l}\text { The extractive } \\
\text { industry driven } \\
\text { development } \\
\text { path. }\end{array}$ & $\begin{array}{l}\text { Same as } \\
\text { Reference- } \\
\text { high. }\end{array}$ & $\begin{array}{l}\text { Including all } \\
\text { planned } \\
\text { projects, } \\
\text { including } \\
\text { those that are } \\
\text { uncertain }\end{array}$ & $\begin{array}{l}\text { Same as } \\
\text { Reference- } \\
\text { high. }\end{array}$ & $\begin{array}{l}\text { Same as } \\
\text { Reference- } \\
\text { high. }\end{array}$ & $\begin{array}{l}\text { Same as } \\
\text { Reference- } \\
\text { high. }\end{array}$ & $\begin{array}{l}\text { Same as } \\
\text { Reference- } \\
\text { high. }\end{array}$ & $\begin{array}{l}\text { Same as } \\
\text { Reference- } \\
\text { medium. }\end{array}$ \\
\hline
\end{tabular}

* Baseline GDP means all sectors excluding extractive industry 


\section{Scenario model}

The scenario model that we developed for this Energy Outlook makes use of the LEAP framework, a medium to long-term modeling tool, designed around the concept of long-range scenario analysis. ${ }^{3}$ The model includes a historical period (2000-2010), in which the model is run to test its ability to replicate known statistical data. Subsequently, the model generates multiple forward looking scenarios for the period 2011-2030. The choice for 2011 as first scenario year is driven by data availability, but also marks the beginning of large scale natural resource exploration in Mozambique.

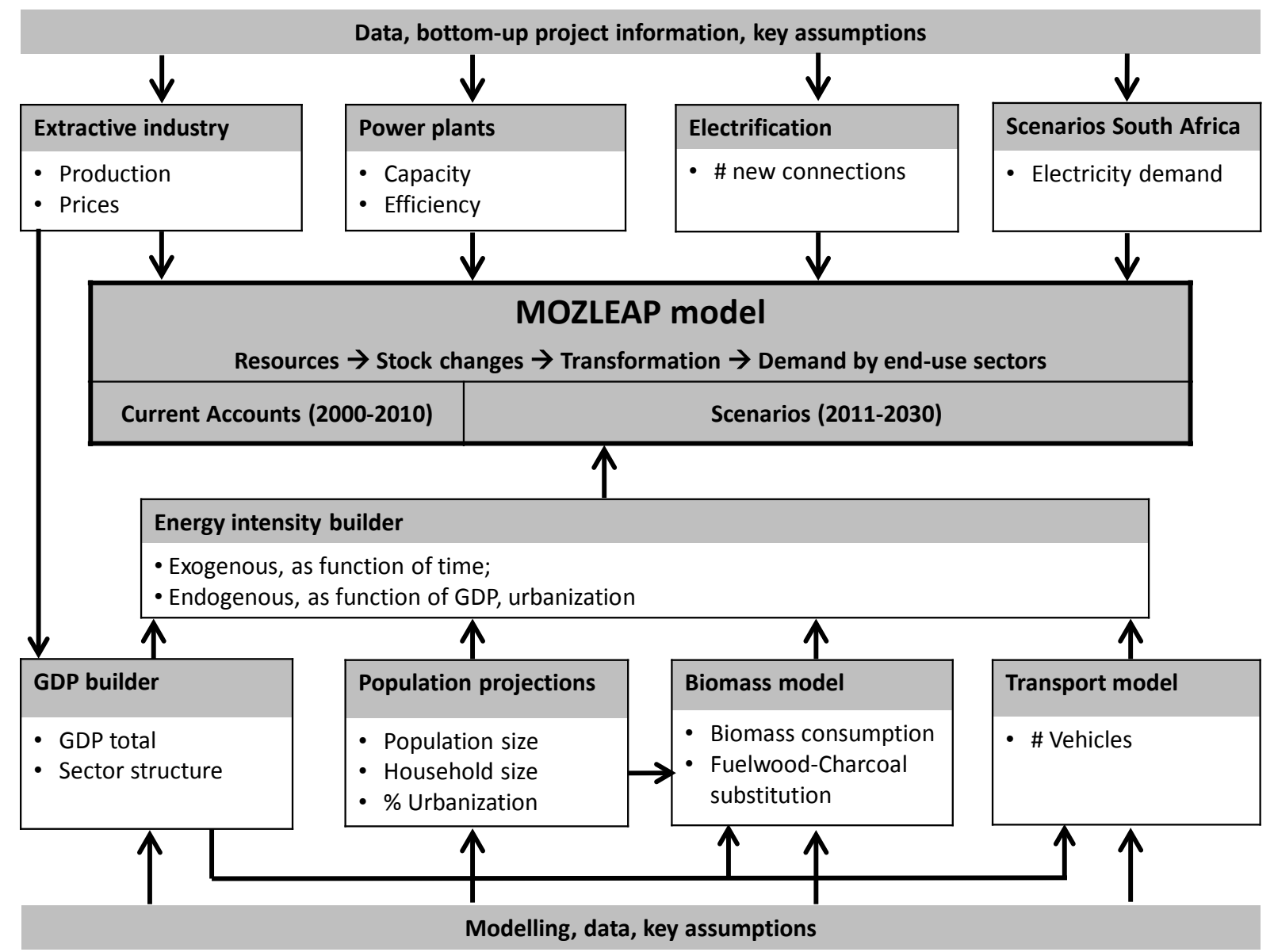

Figure 1. Structure of the modelling framework

\footnotetext{
${ }^{3}$ For more information see www.energycommunity.org
} 
Figure 1 summarizes the structure of our modelling framework. On the supply side, we model electricity production, gas exploration, coal mining and mineral (heavy) sands mining on a project by project basis, using information that we collected about the latest developments and future plans as regards the production and transformation of energy in Mozambique. In addition we develop and integrate into the LEAP framework a simple biomass model to calculate future paths of charcoal production and biomass consumption in Mozambique. On the demand side we adopt a mix of these methodologies to model energy demand by households, transport and extractive industries, as well as the sectors agriculture, manufacturing, services, government and other. Also we specify electricity demand from neighboring countries in the region (especially South Africa), given their essential role in developing the Mozambican electricity market. As regards the demand side, the LEAP accounting framework in essence calculates (future) energy demand as the product of activity levels (such as GDP, population, physical production levels) and energy intensity per unit of activity. Energy demand modeling is based on a combination of historical energy and activity level data, information on demographic and urbanization trends supplied by external sources, locally collected bottom-up information as regards future electricity distribution and cross-country econometric modeling of various GDP elasticities.

In Mahumane and Mulder (2015) we provide an elaborated description of the scenario model, which we have given the name MOZLEAP. For this reason and because of space constraints, here we limit ourselves to a relatively brief account of our modelling approach and its results. Also we refer to the Annexes for more detail on the structure of the model, including its sector sector (Table A.1, Annex B) and the mathematical structure of the sub-models on GDP, biomass and transport fuel consumption (Annex A).

\subsection{GDP}

To model future development paths of GDP we developed a so-called GDP builder that is embedded in LEAP's overall accounting framework. We construct future GDP paths by combining a top-down and bottom-up approach, as follows. We start with historical data from existing sources (Mozambique Central Bank, National Statistics Institute, IMF, Worldbank) on Mozambique's total GDP and its sector structure for the period 2000-2010. From these data series we derive historical GDP growth rates, excluding the extractive industry - which was very small until 2010 (around 1\% of total GDP; see Table 2). We call this baseline GDP growth. Subsequently, adopting a simple top-down approach, for the period 2011-2030 we assume that baseline GDP growth $Y$ follows a declining trend as function of time $t$, according to a logistic curve, such that annual GDP growth gradually evolves towards $3.8 \%-5.9 \%$ by 2030 , depending on the scenario (for details see Table 4, the formulas in Annex A and Table A.2 in Annex B).

Next, using a bottom-up approach, we construct GDP separately for each extractive industry, including the aluminum industry, as follows. First, based on the information in our dataset, we specify per 
existing and planned extractive industry project the expected future production in physical units. We include in our model electricity production, gas exploration, coal mining and mineral (heavy) sands mining. Second, we calculate for each project the GDP value per physical unit of production. To do so, we start with historical data until 2012, which we subsequently extrapolate, assuming a simple but scenariospecific trend based on expected international market prices of the primary resources involved (LNG, heavy sands minerals, coal, aluminum). ${ }^{4}$ Third, we estimate future GDP of the extractive industry by combining these price trends with expected physical production patterns per project, and subsequently aggregating over all projects. Together with the baseline GDP this sums up to total GDP, including an implied total GDP growth rate. Finally, we construct a sectoral breakdown of aggregate GDP by assuming that the respective sector shares of four main sectors (agriculture, services, manufacturing and government) evolve over time as a function of per capita GDP. The results of our GDP calculations are summarized in Table 4.

Table 4. Evolution of GDP across scenarios

\begin{tabular}{|c|c|c|c|c|c|c|c|c|c|c|c|}
\hline \multirow[t]{2}{*}{ Scenarios } & \multirow[t]{2}{*}{ GDP } & \multicolumn{5}{|c|}{ GDP per capita (US\$) } & \multicolumn{5}{|c|}{ GDP growth rate* $(\%)$} \\
\hline & & 2010 & 2015 & 2020 & 2025 & 2030 & 2010 & 2015 & 2020 & 2025 & 2030 \\
\hline \multirow[t]{3}{*}{ Extractive } & Baseline & 403 & 504 & 623 & 749 & 868 & 7,2 & 6,9 & 6,5 & 5,7 & 4,7 \\
\hline & Extractive & 4 & 153 & 328 & 481 & 528 & 5,5 & 20,0 & 14,5 & 3,0 & 2,3 \\
\hline & Total & 407 & 657 & 951 & 1.230 & 1.396 & 7,2 & 9,9 & 9,0 & 4,7 & 3,9 \\
\hline \multirow[t]{3}{*}{ Reference } & Baseline & 403 & 504 & 623 & 749 & 868 & 7,2 & 6,9 & 6,5 & 5,7 & 4,7 \\
\hline & Extractive & 4 & 114 & 205 & 186 & 170 & 5,5 & 27,0 & 6,4 & 0,3 & 0,3 \\
\hline & Total & 407 & 618 & 828 & 935 & 1.039 & 7,2 & 10,6 & 6,4 & 4,6 & 4,0 \\
\hline \multirow[t]{3}{*}{ Reference High } & Baseline & 403 & 509 & 646 & 814 & 1.009 & 7,2 & 7,1 & 6,8 & 6,4 & 5,9 \\
\hline & Extractive & 4 & 114 & 223 & 228 & 235 & 5,5 & 27,0 & 8,6 & 2,3 & 2,3 \\
\hline & Total & 407 & 623 & 869 & 1.042 & 1.244 & 7,2 & 10,7 & 7,3 & 5,5 & 5,2 \\
\hline \multirow[t]{3}{*}{ Reference Low } & Baseline & 403 & 500 & 600 & 690 & 754 & 7,2 & 6,8 & 6,1 & 5,0 & 3,8 \\
\hline & Extractive & 4 & 113 & 188 & 151 & 123 & 5,5 & 27,0 & 4,2 & $-1,7$ & $-1,7$ \\
\hline & Total & 407 & 613 & 788 & 841 & 877 & 7,2 & 10,5 & 5,6 & 3,8 & 3,0 \\
\hline
\end{tabular}

*Average annual growth rate, 3-year moving average.

\footnotetext{
${ }^{4}$ These prices are partly based on expert judgments for the upcoming years, published in a variety of resources (IEA 2013b, KPMG 2013), while for the remaining years price trends are assumed to follow a straightforward but scenario-specific pattern, with annual price fluctuations varying between $-2 \%$ and $4 \%$. Given the expected large relative size of the extractive industry in the future economy of Mozambique, future price trends for primary resources are deliberately designed to be conservative, in order to avoid an upward bias in future GDP development paths. See Table A.2. for further details.
} 
When we look at the last decade and a half, the data clearly illustrate that Mozambique is extremely poor but at the same time experienced rapid economic growth. In 2010 per capita GDP was just over $\$ 400$, in 2015 this is expected to be over $\$ 600$ (which equals to about $\$ 1300$ in PPP terms). These levels roughly correspond with, respectively, $9 \%$ and $2 \%$ of the per capita GDP level in South Africa and the USA and imply that still about half of the Mozambican population lives below the local absolute poverty line (Boom 2011). Yet, the rapid increase in per capita GDP implies that the average annual growth rate of GDP is well over 7\% during the period 2000-2015. In addition, Table 4 shows that our modelling of Baseline GDP leads to a gradual increase of Baseline GDP per capita to levels of \$750$\$ 1000$ by 2030 , depending on the scenario. Furthermore, from Table 4 it can be seen that Extractive GDP per capita is expected to increase dramatically over time, from almost zero in 2000 to $\$ 123-\$ 235$ by 2030 in the Reference scenarios and \$528 in the Extractive scenario. Our assumptions as regards the expansion of production levels in the extractive industry imply that Extractive GDP growth is expected to peak in this decade, and will smooth after 2020. Together these developments cause total per capita GDP to be in the range of $\$ 900-1400$ by 2030 , which equals a $115-243 \%$ increase from 2010 levels.

\subsection{Population}

Size and growth of the population is a key element of our scenario model, because it helps define critical indicators such as per capita GDP, the electrification rate, total residential energy consumption, and fuel consumption by passenger cars. In addition, these indicators are influenced by the composition of the population in terms of the urban-rural divide and whether or not households have access to electricity. In our model, data on historical and future developments of population size and urbanization levels are based on information supplied by Mozambique's National Statistics Institute (INE), cross-checked with the United Nations (UN) population statistics.

As regards population growth, all our scenarios for the period 2011-2030 take as their starting point historic data for the year 2010. In 2010 Mozambique's population was some 22.4 million in total, of which almost $31 \%$ lived in urban areas; average household size was 4.3 , average annual population growth was $2.5 \%$, with urban population growing $3.2 \%$ per year. Subsequently, all scenarios assume population growth to gradually decrease over time; we refer to Table A.2 for a summary of our key demographic assumptions across the various scenarios. As a result, by 2030 total population size is expected to be 32.737.1 million people, with 34.8 million people in the Reference Medium scenario (see Table 5). Growth of urban population is expected to increase to $3.5 \%$ per year in 2030 in the Medium scenario; in the Low and High scenarios we assume this percentage to be $50 \%$ lower and higher, respectively. As a result, by 2030 the percentage of urban population is expected to be $30.8-49.4$, with $39.1 \%$ of urban people in the 
Medium scenario (see Table 5). This implies that in the Medium scenario the number of people living in cities in Mozambique by 2030 is as large as $60 \%$ of the entire population in 2010, which obviously will reshape the urban landscape in Mozambique over the next 25 years, and, hence, transform (residential) energy demand. Finally, in all scenarios we assume the average household size to gradually decrease under influence of income growth and urbanization, from 4.3 persons in 2010 to $4.13-4.25$ persons in 2030.

Table 5. Population, urbanization and electrification

\begin{tabular}{|c|c|c|c|c|c|c|c|}
\hline Scenarios & Element & Unit & 2010 & 2015 & 2020 & 2025 & 2030 \\
\hline \multirow[t]{3}{*}{ Extractive } & Population & Million & 22,4 & 25,1 & 27,6 & 30,1 & 32,7 \\
\hline & Urbanization & $\%$ & 30,9 & 34,1 & 39,8 & 47,2 & 56,1 \\
\hline & Electrification & $\%$ & 15,3 & 25,4 & 32,6 & 37,6 & 40,9 \\
\hline \multirow[t]{3}{*}{ Reference } & Population & Million & 22,4 & 25,2 & 28,2 & 31,4 & 34,8 \\
\hline & Urbanization & $\%$ & 30,9 & 32,3 & 34,2 & 36,5 & 39,1 \\
\hline & Electrification & $\%$ & 15,3 & 25,3 & 32,1 & 36,4 & 38,9 \\
\hline \multirow[t]{3}{*}{ Reference High } & Population & Million & 22,4 & 25,1 & 27,6 & 30,1 & 32,7 \\
\hline & Urbanization & $\%$ & 30,9 & 34,1 & 39,8 & 47,2 & 56,1 \\
\hline & Electrification & $\%$ & 15,3 & 25,7 & 33,7 & 39,9 & 44,7 \\
\hline \multirow[t]{3}{*}{ Reference Low } & Population & Million & 22,4 & 25,4 & 28,9 & 32,9 & 37,1 \\
\hline & Urbanization & $\%$ & 30,9 & 30,6 & 29,2 & 28,1 & 27,1 \\
\hline & Electrification & $\%$ & 15,3 & 25,0 & 30,5 & 33,1 & 33,6 \\
\hline
\end{tabular}

The extent to which the Mozambican population has access to electricity is expected to change rapidly as a result of intensive (rural) electrification programs and growing income levels. In our model the electrification rate is endogenously determined by combining information on electricity network expansion (number of new connections realized) with population growth dynamics as described above. In 2010 the national utility EdM realized 100.000 new connections. In our Reference scenario we expect this number to increase to 135.000 in 2015 , and subsequently decrease to 100.000 in 2030. In our Reference Low and High scenarios, we assume that in 2030 respectively 70.000 and 130.000 new connections will be realized (see Table A.2). Given population growth, this implies that in our model the (household) electrification rate is expected to increase from $15 \%$ in 2010 to $34 \%-45 \%$ in 2030 , with $39 \%$ in the Reference scenario (see Table 5). We assume transmission and distribution losses to remain at $5 \%$ as from 2011. 


\subsection{Biomass}

We model future demand for fuelwood and charcoal by means of a simple biomass model, embedded within LEAP's overall accounting framework. Following micro-based evidence of household energy consumption patterns in developing countries (Barnes and Floor 1999, Barnes et al. 2005), we adopt a nested model structure. First, we assume that total biomass consumption is merely determined by GDP per capita, thus considering substitution with modern energy forms (such as LPG and electricity) as function of relative prices a second-order effect (Leach 1992). Second, we assume that the choice for one of the two dominant forms of biomass (fuelwood and charcoal) is implicitly driven by their relative prices as well as the urbanization rate. More specifically, we first define the evolution of per capita biomass consumption over time according to a logarithmic S-shaped curve that is driven by an initial consumption level, a constant (vertical shift of the curve) and the elasticity of biomass consumption with respect to GDP per capita. Next, we calculate the evolution of the share of charcoal in total biomass consumption as function of the inter-fuel substitution elasticity (i.e. between charcoal and fuelwood) and the annual growth rate urbanization. The fuelwood share is calculated as the remainder.

To allocate charcoal and fuelwood consumption across electrified and non-electrified households, we implemented the following assumptions. First, we assume that in 2000 all electrified households lived in urban areas, and that in 2011 the urban and rural electrification rates were, respectively 55\% and 5\% (IEA 2013). Second, we assume that $5 \%$ of total fuelwood consumption and $85 \%$ of total charcoal consumption is consumed by urban households with the remainder being consumed by rural households (Atanassov, et. al., 2012; Brouwer and Falcão, 2004; INE, 2009). Third, we assume that fuelwood and charcoal is consumed by, respectively, $33 \%$ and $80 \%$ of households in urban areas, while $10 \%$ of households in rural areas consume charcoal. ${ }^{5}$ Finally, building on these assumptions we model future evolution of biomass consumption per electrified household as a function of changes in the total biomass consumption as well as the change in urbanization rate $U$ relative to the change in the electrification rate E. Biomass intensity per non-electrified household is subsequently derived from total biomass consumption not consumed by electrified households. As a result, total biomass consumption in our model declines with increasing GDP, following an inverted S-shaped pattern. As regards its composition, with rising GDP per capita consumption of charcoal increases at the expense of fuelwood consumption, under influence of rising income and urbanization - up to some income threshold level, after which is substituted for modern energy forms such as LPG and electricity. For further details we refer to Annex A.

\footnotetext{
${ }^{5}$ Note that rural electrification has a minor impact on switching of cooking fuel while the opposite is true for urbanization, which is a major driving force for the choice of cooking fuel.
} 


\section{4 (Bio-)fuels}

We model fuel demand for road transport as function of expected evolution of vehicle ownership over time, given per capita GDP and population trends as described before. To this aim we developed a logistic function that is embedded within LEAP's accounting framework. Following evidence from the top-down transport modeling literature in developing countries (Button et al. 1993, Medlock and Soligo 2002) we assume the number of vehicles per 1000 people to be merely determined by GDP per capita, thus considering (relative) fuel prices a second-order effect. Next we calibrate our model by combining this approach with data on the annual evolution of registered vehicles in Mozambique and fuel consumption in the recent past, supplied by, respectively, the Mozambican National Institute of Road Transport (INATTER, 2012) and the Ministry of Energy (ME, 2012). For further details we refer to Annex A.

Mozambique has a large potential for biofuel production, given its climate and a vast amount of unused arable land. At this moment, biofuel production plays only a marginal role in the energy mix. However, the country has adopted a National Program for the Development of Biofuels to promote and use agro-energy resources for energy and food security. In doing so, the government also aims to encourage socioeconomic development and to reduce the country's dependence on fuel imports (IRENA, 2012; Ecoenergy, 2008). The program aims to progressively increase the proportion of biofuel in Mozambique's domestic liquid fuel mix in three phases. The pilot phase (2012-2015) is currently being implemented with a fuel blending mandate of $10 \%$ for bioethanol and $3 \%$ for biodiesel. An operational phase (2016 to 2020) will follow, with $15 \%$ bioethanol and $7.5 \%$ biodiesel blending and conclude with an expansion phase (2021-onwards) of $20 \%$ bioethanol and $10 \%$ biodiesel blending. In our scenarios, we include these phases, but taking into account a 5-year delay to reflect the actual situation.

\subsection{South Africa}

South Africa's power utility (Eskom) has identified Mozambique as a potentially important supplier of electricity in its Integrated Resource Plan 2011 (SA Department of Energy, 2011) to help addressing its future supply-side challenges. Eskom is particularly interested in new hydropower from Mozambique, as the existing electricity generation mix in South Africa is carbon-intensive. Already, HCB represents $40 \%$ of Eskom's carbon-free generation. One of the scenarios in the IRP is to use $2600 \mathrm{MW}$ of power from Mozambique, including 2135 MW from the new hydro projects. Electricity purchases from Natural Gas plants at the Mozambique-RSA border is not looked at in the IRP. As of date, South Africa gets 92 MW from Gigawatt plant in Ressano-Garcia, and could get an additional $150 \mathrm{MW}$ from Sasol's plant in the same area. According to the IRP, South Africa needs an additional 90 GW of generating capacity by 2030, mostly from renewables. Therefore in our Extractive Scenario, we have modeled 3320 MW of capacity dedicated to Eskom, of which 1900 to 2100 MW would have to be firm. 


\subsection{Energy Intensity}

We assume that in various sectors of our model the evolution of energy intensity is a function of GDP growth, reflecting the notion of increasing energy efficiency under economic development (Lescaroux 2011). For the period 2000-2010 energy intensity values are calculated based on historical data regarding energy consumption and activity levels on a sector by sector basis. Subsequently, future energy intensity values for the period 2011-2030 are calculated on the basis of a variety of simple assumptions, again on a sector by sector basis. ${ }^{6}$ We refer to Table A.3 in the Annex B for a detailed summary of our assumptions as regards future energy intensity trends across the various end-use sectors.

In short, we assume that in a poor country like Mozambique electricity consumption per household increases over time under influence of rising GDP, because growing household income leads to increasing demand for electric appliances such as refrigerators and air conditioning. Also, we assume that LPG consumption per household increases over time under influence of rising GDP as well as the degree of urbanization, because growing household income leads to a shift towards modern cooking fuels, while in developing countries LPG is a typical urban fuel for logistic reasons. Furthermore, we assume that kerosene consumption per household decreases over time, because of a gradual 'autonomous' substitution towards more efficient and cleaner fuels like electricity and LPG. Finally, future charcoal and fuelwood intensities are derived from our biomass model.

For the Agriculture sector we assume that energy intensity increases with about $20 \%$ over the course of 20 years, under influence of modernization and mechanization. In the Manufacturing sector, we assume that Mozal's production process does not change over time; future energy intensity values and fuel shares are therefore constant and based on historical data. In the Other Industry sector we assume that energy intensity increases at a decreasing pace, driven by the opposing forces of modernization and increasing energy efficiency. In the sector Commercial Services. Government and Other we assume that electricity intensity increases with economic growth, In Services we assume that LPG consumption (in hotels and restaurants) depends positively on the degree of urbanization.

Energy intensity in the extractive industry is determined by constant values of electricity and diesel consumption per physical unit of production. Actual values originate from a combination of indicative figures on open-cut coal mining and mineral sands explorations reported in the literature (Bleiwas 2011; SEE 2009) and from personal communications with local experts involved in mining activities in Mozambique. Finally, fuel efficiency in road transport is assumed to gradually increase over time under influence of economic development, whereas fuel intensity for tractors is assumed to increase because of the expected increasing use of heavy equipment as economic development proceeds.

\footnotetext{
${ }^{6}$ Given Mozambique's current status as an extremely poor country with a rapidly expanding energy sector, we decided to leave a careful analysis of energy efficiency improvements in end-use sectors for future research.
} 


\section{Outlook energy supply}

In this section we present an outlook for energy production in Mozambique, according to the scenario methodology described in the previous sections. As illustrated in Figure 2, we expect in the reference scenario that total primary production increases from almost 14 million toe in 2011 to over 90 million toe in 2030. If Mozambique were to follow the extractive scenario development path, primary production could even increase to a level of 180 million toe in 2030. This equals a 6 to 13 -fold increase in primary energy production in less than 20 years. As can be seen from the upper part of Figure 2, natural gas and coal together will make up for $80-90 \%$ of these production levels. In contrast, at the turn of the century 80 90\% of total energy production in Mozambique consisted of wood, with hydro largely making up for the remaining 10-20\%. ${ }^{7}$ Nevertheless, according to our scenarios total energy production from wood and hydro are expected to increase $60-90 \%$ over the next 15 years; yet the emergence of natural gas and coal are causing their relative shares in total energy production to decrease to about 3\% (hydro) and 10\% in 2030. Clearly, together this means that Mozambique will undergo no less than a revolution at the supply side of its energy sector.

The lower part of Figure 2 shows that $80-90 \%$ of total energy production in Mozambique is expected to be destined for export. This is especially true for the natural gas and coal production, but to a lesser extent also for hydro, which continues to be exported to South Africa and other neighboring countries in the form of electricity (more on this below). The natural destination for coal is India, but Brazil is also expected to be a market for Mozambique's coal export (IEA 2014). Of course, energy production from wood and solar almost exclusively serves the domestic market. We refer to Table 6 for a more detailed overview of the destination of primary energy production per energy source, including its (end-use) form.

\footnotetext{
${ }^{7}$ We exclude Solar and Diesel from Figures 2 and 3 because their values are too small to visualize.
} 

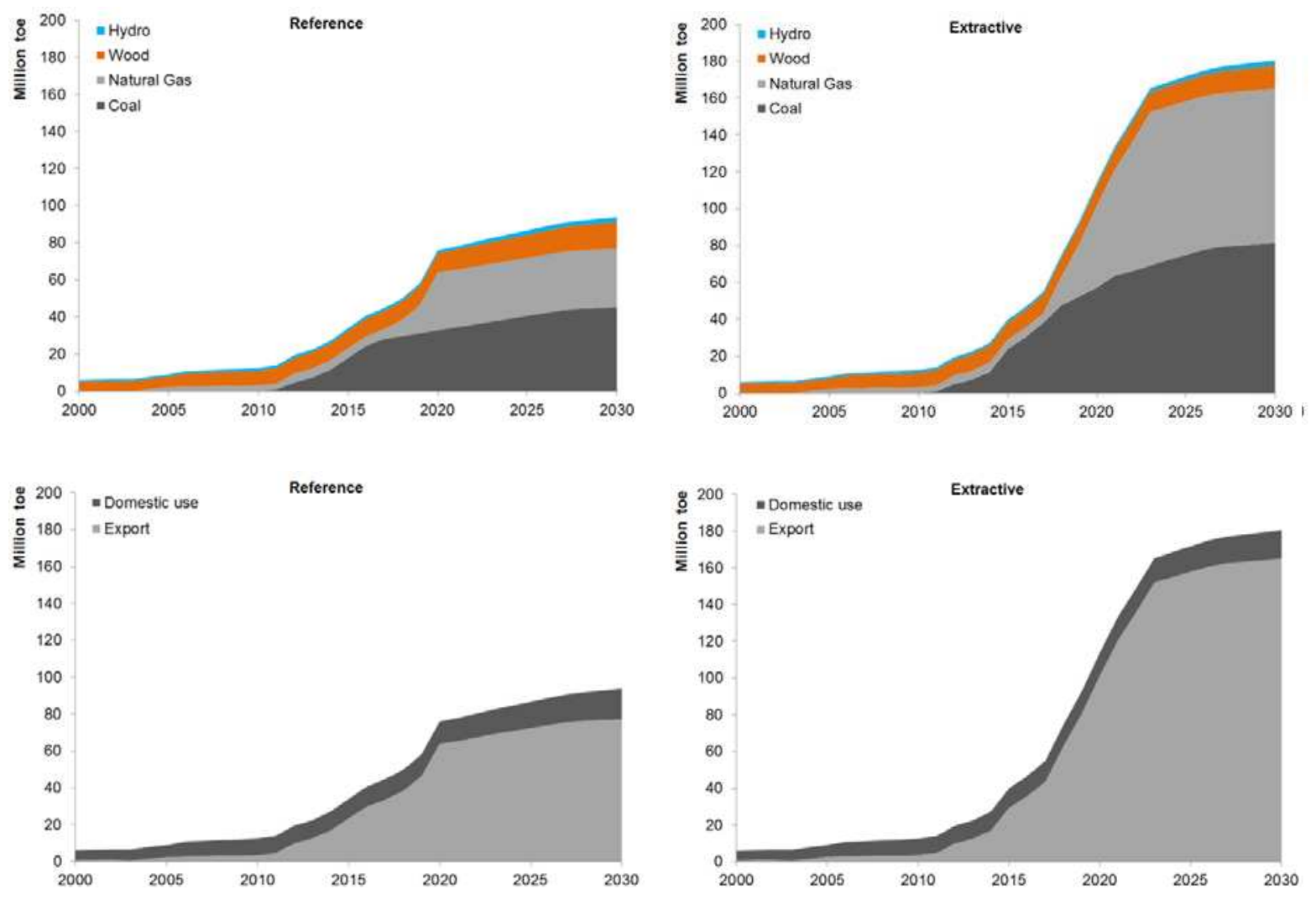

Figure 2. Total primary energy production by source (top) and destination (bottom). 
Table 6a. Destination of primary energy production by energy type (1000 TOE) - Reference scenario

\begin{tabular}{|c|c|c|c|c|c|c|c|c|c|}
\hline \multirow[t]{2}{*}{ Energy type } & \multirow[t]{2}{*}{ Destination } & \multirow[t]{2}{*}{ Energy form } & \multirow[t]{2}{*}{ Use } & \multicolumn{5}{|c|}{ Reference scenario } & \multirow{2}{*}{$\frac{\% \text { change }}{2015-30}$} \\
\hline & & & & 2010 & 2015 & 2020 & 2025 & 2030 & \\
\hline \multirow[t]{4}{*}{ Natural Gas } & Domestic use & Primary & End use & 69,8 & 116,0 & 148,3 & 209,0 & 286,2 & $147 \%$ \\
\hline & & Secondary & Electricity Generation & 0,9 & 196,8 & 243,4 & 200,1 & 220,9 & $12 \%$ \\
\hline & Export & Primary & End use & $2.967,1$ & $4.376,0$ & $29.980,2$ & $30.203,5$ & $30.438,1$ & $596 \%$ \\
\hline & & Secondary & Electricity & 3,2 & 536,7 & 642,8 & 686,1 & 665,3 & $24 \%$ \\
\hline \multirow[t]{3}{*}{ Coal } & Domestic use & Secondary & Electricity Generation & 0,0 & 0,0 & 205,0 & 168,5 & 186,0 & -- \\
\hline & Export & Primary & End use & 25,6 & $17.919,8$ & $31.918,9$ & $39.675,4$ & $44.265,2$ & $147 \%$ \\
\hline & & Secondary & Electricity & 0,0 & 0,0 & 676,9 & 713,3 & 695,8 & -- \\
\hline \multirow[t]{2}{*}{ Wood } & Domestic use & Primary & End use & $4.563,3$ & $4.767,2$ & $4.782,6$ & $4.798,1$ & $4.649,8$ & $-2 \%$ \\
\hline & & Secondary & Charcoal making & $3.470,7$ & $4.529,8$ & $5.810,6$ & $7.611,4$ & $9.865,1$ & $118 \%$ \\
\hline \multirow[t]{2}{*}{ Hydro } & Domestic use & Secondary & Electricity Generation & 937,7 & 978,8 & 985,1 & $1.281,9$ & $1.460,9$ & $49 \%$ \\
\hline & Export & Secondary & Electricity & 494,9 & 537,6 & 539,3 & $1.130,8$ & $1.030,3$ & $92 \%$ \\
\hline \multirow[t]{2}{*}{ Solar } & Domestic use & Secondary & Electricity Generation & 0,4 & 1,0 & 2,1 & 3,5 & 7,7 & $639 \%$ \\
\hline & Export & Secondary & Electricity & 0,2 & 0,6 & 1,1 & 3,1 & 5,4 & $849 \%$ \\
\hline
\end{tabular}


Table 6b. Destination of primary energy production by energy type (1000 TOE) - Extractive scenario

\begin{tabular}{|c|c|c|c|c|c|c|c|c|c|}
\hline \multirow[t]{2}{*}{ Energy type } & \multirow[t]{2}{*}{ Destination } & \multirow[t]{2}{*}{ Energy form } & \multirow[t]{2}{*}{ Use } & \multicolumn{5}{|c|}{ Extractive scenario } & \multirow{2}{*}{$\begin{array}{r}\% \text { change } \\
2015-30\end{array}$} \\
\hline & & & & 2010 & 2015 & 2020 & 2025 & 2030 & \\
\hline \multirow[t]{4}{*}{ Natural Gas } & Domestic use & Primary & End use & 70,7 & 311,5 & 535,6 & 634,6 & 699,8 & $125 \%$ \\
\hline & & Secondary & Electricity Generation & 69,8 & 116,1 & 158,5 & 221,3 & 302,2 & $160 \%$ \\
\hline & Export & Primary & End use & $2.967,1$ & $4.376,0$ & $42.782,4$ & $81.412,0$ & $81.646,6$ & $1766 \%$ \\
\hline & & Secondary & Electricity & 3,2 & 531,2 & $1.136,3$ & $1.286,3$ & $1.302,0$ & $145 \%$ \\
\hline \multirow[t]{3}{*}{ Coal } & Domestic use & Secondary & Electricity Generation & 0,0 & 0,0 & 464,9 & 670,5 & 645,1 & -- \\
\hline & Export & Primary & End use & 25,6 & $23.700,4$ & $54.956,4$ & $71.742,3$ & $78.213,0$ & $230 \%$ \\
\hline & & Secondary & Electricity & 0,0 & 0,0 & $1.706,9$ & $2.528,3$ & $2.553,6$ & -- \\
\hline \multirow[t]{2}{*}{ Wood } & Domestic use & Primary & End use & $4.563,3$ & $4.640,1$ & $4.254,9$ & $3.461,2$ & $2.679,0$ & $-42 \%$ \\
\hline & & Secondary & Charcoal making & $3.470,7$ & $4.698,8$ & $6.255,5$ & $7.805,1$ & $9.967,0$ & $112 \%$ \\
\hline \multirow[t]{2}{*}{ Hydro } & Domestic use & Secondary & Electricity Generation & 937,7 & $1.005,4$ & $1.029,6$ & $1.347,6$ & $1.619,3$ & $61 \%$ \\
\hline & Export & Secondary & Electricity & 494,9 & 549,0 & 683,3 & 937,1 & $1.234,0$ & $125 \%$ \\
\hline \multirow[t]{2}{*}{ Solar } & Domestic use & Secondary & Electricity Generation & 0,4 & 1,0 & 1,9 & 3,8 & 7,4 & $621 \%$ \\
\hline & Export & Secondary & Electricity & 0,2 & 0,6 & 1,3 & 2,7 & 5,7 & $906 \%$ \\
\hline
\end{tabular}


As a consequence of the current energy revolution, Mozambique is rapidly developing into an important player at international energy markets, especially when it comes to natural gas and coal. To assess this trend we compare in Table 7 the expected production and export levels of natural gas and coal by Mozambique in 2030 (according to our scenarios) with the equivalent production and export levels by the current (2013) global Top-10 countries. From this Table it can be seen that Mozambique is expected to develop into, respectively, a global Top-20 producer and Top-10 exporter of Natural Gas and Coal. The emergence of Mozambique as a major exporter of these fossil fuels is of course due to the combination of sizeable future production and a relatively small domestic economy, as a result of which its primary energy production will be largely exported.

Table 7. Mozambique 2030 compared to the current (2013) top-10 countries for production and export of natural gas and coal.

\begin{tabular}{|c|c|c|c|c|c|}
\hline \multicolumn{6}{|c|}{ Natural Gas } \\
\hline \multicolumn{3}{|c|}{ Production } & \multicolumn{3}{|c|}{ Exports } \\
\hline 1 & US & 627,2 & 1 & Russian Federation & 250,6 \\
\hline 2 & Russian Federation & 544,3 & 2 & Qatar & 138,4 \\
\hline 3 & Iran & 149,9 & 3 & Norway & 118,0 \\
\hline 4 & Qatar & 142,7 & 4 & Canada & 87,6 \\
\hline 5 & Canada & 139,3 & 5 & Mozambique 2030, Extractive & 81,6 \\
\hline 6 & China & 105,3 & 6 & Netherlands & 59,3 \\
\hline 7 & Norway & 97,9 & 7 & US & 49,5 \\
\hline 8 & Saudi Arabia & 92,7 & 8 & Algeria & 47,7 \\
\hline 9 & Mozambique 2030, Extractive & 84,0 & 9 & Indonesia & 34,8 \\
\hline 10 & Algeria & 70,7 & 10 & Mozambique 2030, Reference & 30,4 \\
\hline \multirow[t]{3}{*}{26} & Mozambique 2030, Reference & 31,6 & & & \\
\hline & \multicolumn{5}{|c|}{ Coal } \\
\hline & Production & & \multicolumn{3}{|c|}{ Export } \\
\hline 1 & China & 1840,0 & 1 & Indonesia & 247,1 \\
\hline 2 & US & 500,5 & 2 & Australia & 194,3 \\
\hline 3 & Australia & 269,1 & 3 & Russia & 78,7 \\
\hline 4 & Indonesia & 258,9 & 4 & United States & 78,4 \\
\hline 5 & India & 228,8 & 5 & Mozambique 2030, Extractive & 78,2 \\
\hline 6 & Russian Federation & 165,1 & 6 & Colombia & 56,8 \\
\hline 7 & South Africa & 144,7 & 7 & South Africa & 52,2 \\
\hline 8 & Mozambique 2030, Extractive & 81,4 & 8 & Mozambique 2030, Reference & 44,2 \\
\hline 9 & Kazakhstan & 58,4 & 9 & Canada & 22,0 \\
\hline 10 & Poland & 57,6 & 10 & Kazakhstan & 14,8 \\
\hline 13 & Mozambique 2030, Reference & 45,1 & & & \\
\hline
\end{tabular}

Million tonnes oil equivalent. Source: BP

In addition, Mozambique is expected to strengthen its position as an important player in the regional market for electricity. Based on our information and assumptions as regards future electricity generation projects, we present in Figure 3 the expected future development paths of electricity production 
per energy source. From Figure 3 it can be seen that total electricity production is at least expected to more than double from about $16 \mathrm{GWh}$ in 2011 to $37 \mathrm{GWh}$ in 2030 (Reference scenario), while it could also triple to about $54 \mathrm{GWh}$ in 2030 if Mozambique were to follow the extractive scenario in this respect. Figure 3 also illustrates that hydro remains the main source of electricity production, thanks to the existing Cahora Bassa Hydroelectric (HCB) dam in combination with planned future construction of other major hydro projects, including HCB-North and Mphanda Nkuwa. However, the share of hydro in total electricity generation mix is expected to decrease as a result of the expected construction of thermal power plants fueled by natural gas and coal. Because of HCB's dominance, until recently hydro was responsible for virtually $100 \%$ of electricity production in Mozambique, whereas by 2030 natural gas and coal together are expected to account for about $20-40 \%$ of total electricity production, depending on the scenario.
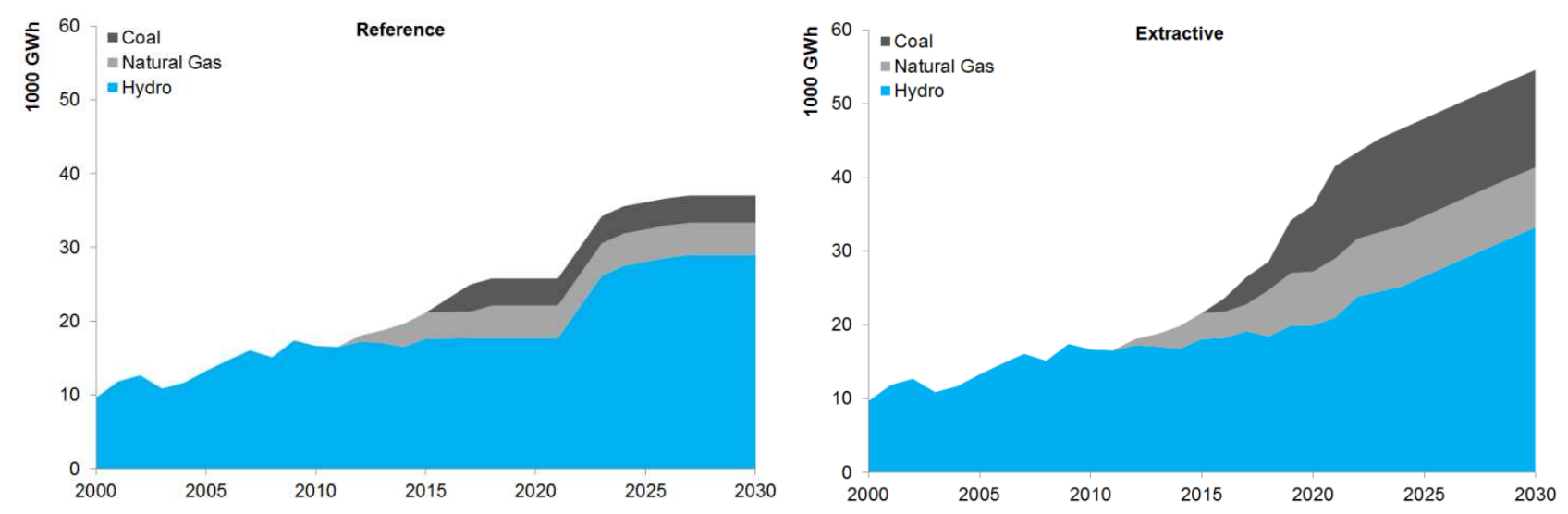

Figure 3. Electricity generation by source

As noted before, our electricity supply projections are primarily based on information and assumptions as regards future electricity generation projects. Total capacity is anticipated to meet the combined effect of increased power demand from South Africa, a range of coal and heavy sands mining projects, and other domestic demand. Figure 4 illustrates that existing and future electricity generation projects would produce more than enough to supply domestic electricity demand under various scenarios of demand growth (see next section). More precisely, from the Figure it can be seen that only about half of expected total electricity generation capacity is needed to meet domestic electricity demand, while the other half thus serves electricity demand from neighboring countries, especially South Africa. Consequently, realization of future electricity generation projects heavily depends on the willingness of the South African power utility ESKOM to reach long term agreements with Mozambique to meet its own 
future demand. Hence, demand from South Africa will continue be the main driver for electricity capacity addition in the future.
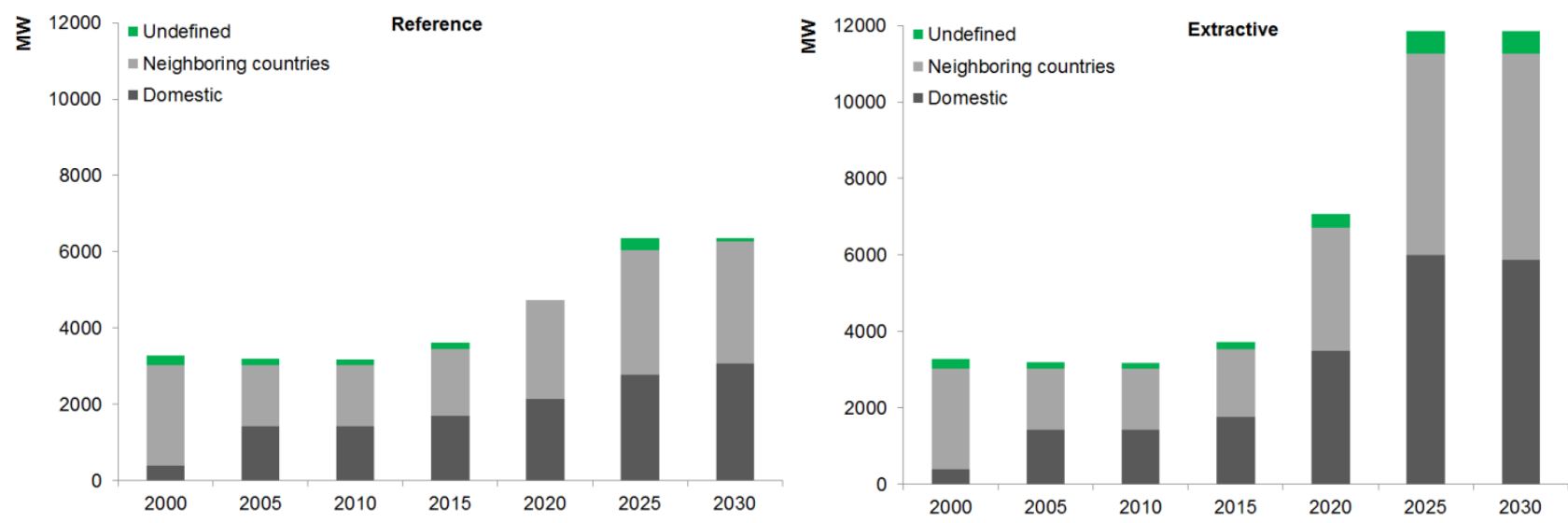

Figure 4. Electricity production capacity by destination. 


\section{Outlook energy demand}

In this section we conclude our analysis by presenting an outlook for energy demand in Mozambique. We do so by first presenting in Figure 5 for each of the four scenarios the evolution of total final energy consumption per sector until 2030. From the Figure it can be seen that in the Reference scenario total energy demand is expected to increase to 11.6 thousand toe in 2030. This is a $60 \%$ increase from the 2011 level of energy demand, and equivalent to an average annual increase of $2.6 \%$ as from 2011. If Mozambique were to follow the Reference Low development path, total final energy consumption is expected to reach 12.3 thousand toe in 2030, which equals an average annual increase of energy demand of $2.9 \%$ as from 2011. In contrast, the lowest level of energy consumption is to be expected if Mozambique were to follow the Extractive Scenario development path - with an estimated total final energy demand of 10.6 thousand toe in 2030, implying a $2.1 \%$ average annual increase over the period 2011-2030. The evolution of total final energy demand in the Reference High scenario is very similar to the Extractive scenario, notwithstanding differences in its composition.
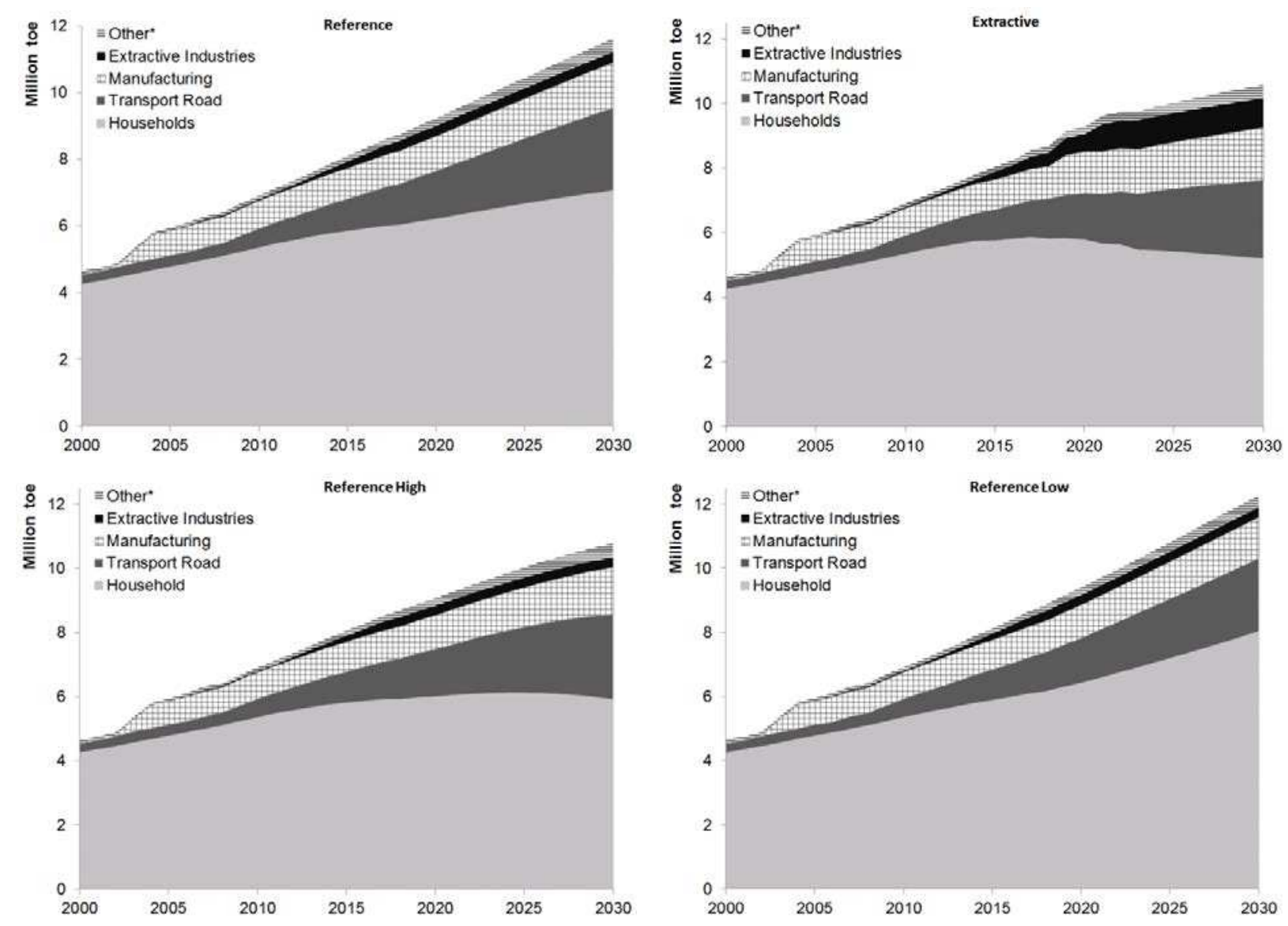

Figure 5. Total final energy consumption by sector. 
It may appear at first sight somewhat counterintuitive that in the long run the Reference Low scenario yields a considerably higher level of aggregate energy demand than the Extractive or Reference High scenario - surely the latter scenarios include high economic growth and extractive industry expansion. The breakdown of total final energy consumption by end-use sectors in Figure 5 clearly shows that this result is to be explained entirely by the evolution of energy demand from the household sector. Given the relatively small size of the underdeveloped Mozambican economy, the residential sector is and remains responsible for a large part of total energy consumption in Mozambique (over $90 \%$ in 2000 and $50-60 \%$ in 2030). Figure 5 shows that residential energy demand continues to grow relatively strong over time in the Reference Low scenario, whereas it decreases relatively rapid in the Extractive and Reference scenarios. As we will show in more detail below (see Table 8), the most important underlying reason for these diverging patterns of residential energy consumption is a straightforward scale effect: over time the number of households becomes much smaller in the Extractive and Reference High scenario than in the Reference Low scenario. This feature of our model of course follows from our assumption that population growth is inversely related to GDP growth (see section 5.2). Hence, it is in the high economic growth scenarios that the weight of the dominant households sector in driving total energy demand decreases most. In addition there is an intensity effect: household energy intensity will decrease relatively rapidly over time in the high economic growth scenarios, given that our model assumes that households substitute away from inefficient biomass consumption towards the use of modern and more efficient energy types like LPG and electricity under influence of increasing per capita GDP (see section 5.4). These developments are clearly illustrated in Figure 6 and Table 8 - more on this later in the section.

As regards the non-residential sectors, Figure 5 shows that the Extractive scenario, obviously, stands out in terms of a relative strong energy demand growth from the extractive and manufacturing sectors. According to this scenario, by 2030 energy demand of extractive industries equals just over 900 thousand toe, which is 3 times more than in the Reference scenario. As noted before, energy demand in the manufacturing sector is largely driven by MOZAL; in the Extractive Scenario total energy demand from this sector is expected to record a major growth peak by 2019/20 following the expansion of MOZAL, to reach about 1600 thousand toe in 2030. Finally, demand by road transport varies only to a relatively limited extent among the various scenarios, with an annual growth of about 7\%; as a result demand for fuel transport is expected to more than quadruple by 2030 as compared to 2010.

We continue our analysis by presenting in Figure 6 the composition of total final energy consumption over time in terms of energy types, for each of the four scenarios over time and expressed in percentage shares. Figure 6 clearly shows the dominant role of traditional biomass consumption in Mozambique - in absolute terms as well as with respect to its role in explaining differences across scenario. In the Reference scenario the share of fuelwood consumption in total final energy consumption 
reduces from over $80 \%$ in 2000 to $40 \%$ in 2030; in the scenarios Extractive and Reference High the share of fuelwood consumption falls to, respectively, $25 \%$ and $29 \%$ in 2030, whereas in the Reference Low scenario fuelwood still makes up for $50 \%$ of total finale energy consumption in 2030. The gradual substitution of charcoal for fuelwood under influence of increasing per capita GDP causes the charcoal share to increase from $8 \%$ in 2000 to $17 \%$ in 2030 in the Reference scenario. In the scenarios Extractive and Reference High this share increases somewhat further to $19 \%$ and $21 \%$ in 2030 , respectively. In the Reference Low scenario this substitution process is relatively slow, with charcoal consumption reaching only $13 \%$ of total final energy demand by 2030 . Together, these numbers imply that even in the high economic growth scenarios (Extractive and Reference High) traditional biomass consumption remains responsible for $44-50 \%$ of total final energy consumption by 2030 ; in the low growth scenario (Reference Low) this percentage is $62 \%$. Given its dominant role in the total fuel mix, we take a closer look at biomass consumption further below in this section.
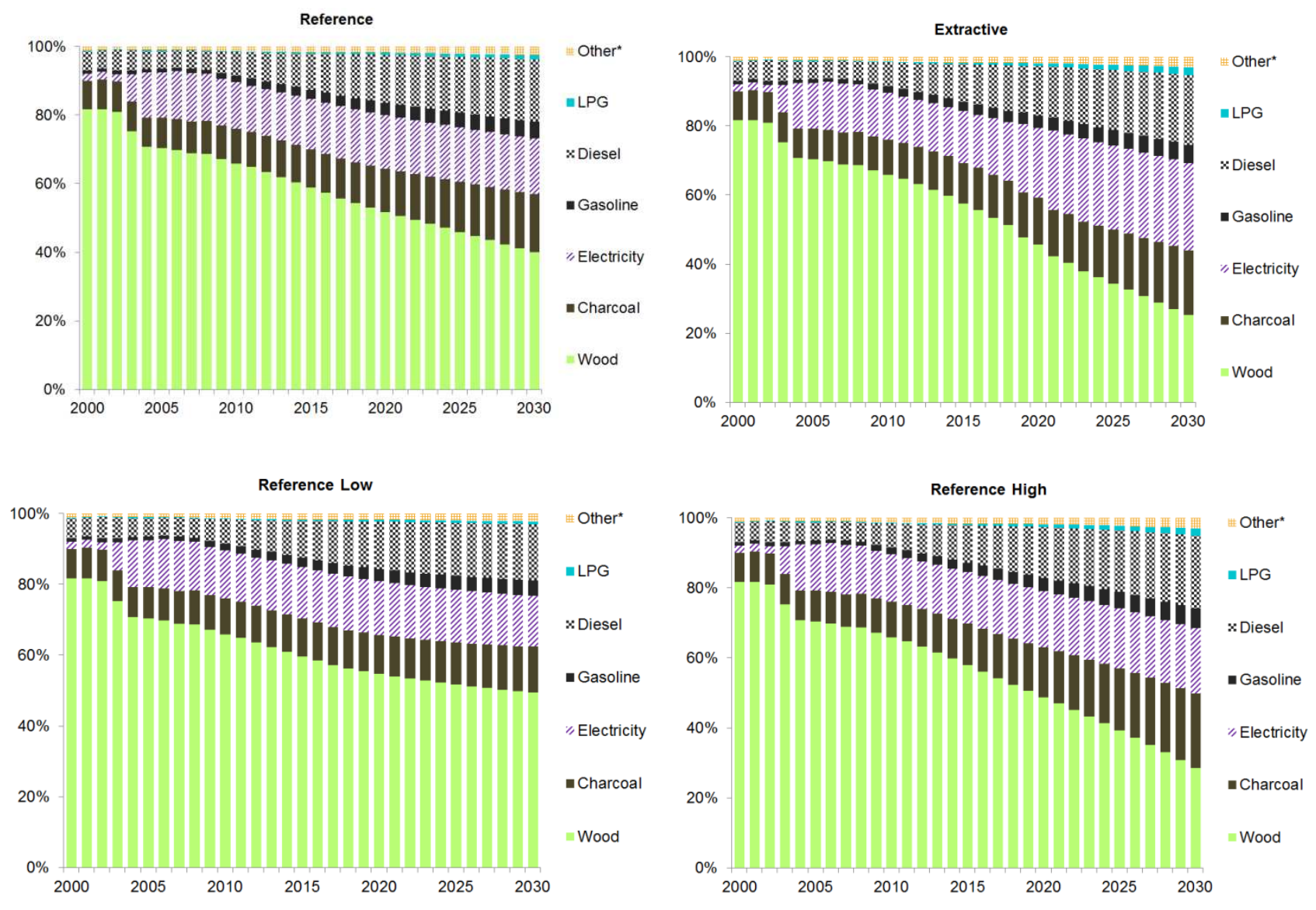

Figure 6. Total final energy consumption by energy type 
Figure 6 also illustrates the relatively strong growth of Diesel and Electricity consumption over time. The abrupt large increase of the electricity share in 2003-4 of course originates from the opening of the aluminum smelter Mozal - at that time responsible for about $90 \%$ of all electricity consumption in the country. Economic growth, continued electrification efforts and extractive industry expansion lead to a firm increase in electricity consumption over time: underlying data tell that in the various Reference scenarios from almost 100 thousand toe in 2000 to a range of 1800-2000 thousand toe in 2030, and in the Extractive scenario even to about 27 thousand toe in 2030. From Figure 6 it can be seen that these spectacular growth figures do not translate in a strong increase of the share of electricity in total final energy consumption, because of the emergence of other energy types - most notably Diesel and Charcoal. In short, the share of electricity in the energy mix increases from 13\% in 2005 (just after Mozal was producing at full capacity) to only $14-19 \%$ by 2030 in the various Reference scenarios, and to $25 \%$ in the Extractive scenario. At the end of this section we present some further analyses of electricity demand. The strong increase in Diesel consumption, clearly visible in Figure 6, is driven by a strong increase in vehicle ownership, in combination with increasing demand from the expanding mining sector. This leads to an increase in the share of Diesel consumption from $8 \%$ in 2000 to about $20 \%$ in 2030, depending on the scenario. Fuel demand for transport is responsible for about $90 \%$ of this increase, the remaining part comes from increased use of diesel by the mining sector. Finally, Figure 6 shows that although the share of LPG gradually increases over time it is expected to play a minor role in the overall fuel mix with up to $2 \%$ by 2030.

To assess the factors that drive these patterns, we decompose in Table $8 \mathrm{a}$ for each scenario total household energy demand per energy type as well as socio-economic driving force, expressed in terms of the deviation from the Reference scenario. In Table $8 \mathrm{~b}$ we present results from the same exercise for the non-residential sectors. From the left-hand side of Table 8a it can be clearly seen that, in terms of energy types, differences in fuelwood consumption across the scenarios largely explain the observed differences in total residential energy demand across the scenarios. The right-hand side of Table 8 a shows that in terms of socio-economic factors population size and per capita GDP together explain almost all of the observed differences in residential energy demand across scenarios. In short, in the scenarios Extractive and Reference High the relatively low residential energy consumption is mainly driven by a relatively small number of households that, under influence of relatively rapid increasing per capita GDP, is over time substituting away from fuelwood to charcoal and (to a lesser extent) LPG and electricity to meet their energy needs. ${ }^{8}$ The opposite is true for the scenario Reference Low. Across all scenarios the role of urbanization, which impacts LPG use (see section 5) and electrification is relatively small.

\footnotetext{
${ }^{8}$ Interestingly, our calculations thus show that the intensity effect outweighs the income effect from increasing per capita GDP.
} 
Table 8a. Residential energy demand - Difference with Reference scenario in terms of fuels and driving forces

\begin{tabular}{|c|c|c|c|c|c|c|c|c|c|c|}
\hline & & 2015 & 2020 & 2025 & 2030 & & 2015 & 2020 & 2025 & 2030 \\
\hline \multirow[t]{7}{*}{ Extractive } & TOTAL (1000 toe) & -89 & -422 & -1.248 & -1.863 & TOTAL (1000 toe) & -89 & -422 & -1.248 & -1.863 \\
\hline & Electricity & $1 \%$ & $1 \%$ & $1 \%$ & $0 \%$ & Population & $-46 \%$ & $-42 \%$ & $-34 \%$ & $-40 \%$ \\
\hline & LPG & $4 \%$ & $3 \%$ & $3 \%$ & $4 \%$ & Urbanization & $2 \%$ & $2 \%$ & $2 \%$ & $3 \%$ \\
\hline & Kerosene & $0 \%$ & $0 \%$ & $0 \%$ & $0 \%$ & Electrification & $0 \%$ & $0 \%$ & $0 \%$ & $0 \%$ \\
\hline & Charcoal & $38 \%$ & $21 \%$ & $3 \%$ & $1 \%$ & GDP per capita & $-56 \%$ & $-61 \%$ & $-71 \%$ & $-66 \%$ \\
\hline & Fuelwood & $-142 \%$ & $-125 \%$ & $-107 \%$ & $-106 \%$ & Other & $0 \%$ & $2 \%$ & $3 \%$ & $3 \%$ \\
\hline & TOTAL & $-100 \%$ & $-100 \%$ & $-100 \%$ & $-100 \%$ & TOTAL & $-100 \%$ & $-100 \%$ & $-100 \%$ & $-100 \%$ \\
\hline \multirow[t]{6}{*}{ Reference High } & TOTAL (1000 toe) & -40 & -208 & -553 & -1.148 & TOTAL (1000 toe) & -40 & -208 & -553 & -1.148 \\
\hline & Electricity & $4 \%$ & $4 \%$ & $4 \%$ & $3 \%$ & Population & $-103 \%$ & $-83 \%$ & $-71 \%$ & $-62 \%$ \\
\hline & LPG & $4 \%$ & $4 \%$ & $5 \%$ & $5 \%$ & Urbanization & $4 \%$ & $4 \%$ & $4 \%$ & $4 \%$ \\
\hline & Kerosene & $0 \%$ & $0 \%$ & $0 \%$ & $0 \%$ & Electrification & $4 \%$ & $4 \%$ & $3 \%$ & $3 \%$ \\
\hline & Fuelwood & $-214 \%$ & $-174 \%$ & $-154 \%$ & $-136 \%$ & Other & $0 \%$ & $1 \%$ & $3 \%$ & $4 \%$ \\
\hline & TOTAL & $-100 \%$ & $-100 \%$ & $-100 \%$ & $-100 \%$ & TOTAL & $-100 \%$ & $-100 \%$ & $-100 \%$ & $-100 \%$ \\
\hline \multirow[t]{7}{*}{ Reference Low } & TOTAL (1000 toe) & 42 & 217 & 523 & 968 & TOTAL (1000 toe) & 42 & 217 & 523 & 968 \\
\hline & Electricity & $-4 \%$ & $-4 \%$ & $-4 \%$ & $-4 \%$ & Population & $103 \%$ & $85 \%$ & $76 \%$ & $69 \%$ \\
\hline & LPG & $-3 \%$ & $-3 \%$ & $-4 \%$ & $-4 \%$ & Urbanization & $-3 \%$ & $-3 \%$ & $-3 \%$ & $-3 \%$ \\
\hline & Kerosene & $0 \%$ & $0 \%$ & $0 \%$ & $0 \%$ & Electrification & $-4 \%$ & $-3 \%$ & $-3 \%$ & $-3 \%$ \\
\hline & Charcoal & $-96 \%$ & $-58 \%$ & $-46 \%$ & $-39 \%$ & GDP per capita & $4 \%$ & $21 \%$ & $28 \%$ & $33 \%$ \\
\hline & Fuelwood & $203 \%$ & $165 \%$ & $153 \%$ & $147 \%$ & Other & $0 \%$ & $1 \%$ & $2 \%$ & $4 \%$ \\
\hline & TOTAL & $100 \%$ & $100 \%$ & $100 \%$ & $100 \%$ & TOTAL & $100 \%$ & $100 \%$ & $100 \%$ & $100 \%$ \\
\hline
\end{tabular}


Table 8b. Non-Residential energy demand - Difference with Reference scenario in terms of fuels and driving forces

\begin{tabular}{|c|c|c|c|c|c|c|c|c|c|c|}
\hline & & 2015 & 2020 & 2025 & 2030 & & 2015 & 2020 & 2025 & 2030 \\
\hline \multirow[t]{7}{*}{ Extractive } & TOTAL (1000 toe) & 49 & 518 & 972 & 1.161 & TOTAL (1000 toe) & 49 & 518 & 972 & 1.161 \\
\hline & Electricity & $55 \%$ & $90 \%$ & $92 \%$ & $93 \%$ & Population & $10 \%$ & $3 \%$ & $2 \%$ & $0 \%$ \\
\hline & Diesel \& Gasoline & $43 \%$ & $7 \%$ & $5 \%$ & $3 \%$ & Urbanization & $1 \%$ & $0 \%$ & $1 \%$ & $1 \%$ \\
\hline & Natural Gas & $0 \%$ & $2 \%$ & $1 \%$ & $2 \%$ & Electrification & $0 \%$ & $0 \%$ & $0 \%$ & $0 \%$ \\
\hline & LPG & $2 \%$ & $1 \%$ & $1 \%$ & $2 \%$ & GDP per capita & $89 \%$ & $97 \%$ & $97 \%$ & $98 \%$ \\
\hline & Charcoal & $0 \%$ & $0 \%$ & $0 \%$ & $0 \%$ & Other & $0 \%$ & $0 \%$ & $0 \%$ & $1 \%$ \\
\hline & TOTAL & $100 \%$ & $100 \%$ & $100 \%$ & $100 \%$ & TOTAL & $100 \%$ & $100 \%$ & $100 \%$ & $100 \%$ \\
\hline \multirow[t]{7}{*}{ Reference High } & TOTAL (1000 toe) & 10 & 54 & 155 & 338 & TOTAL (1000 toe) & 10 & 54 & 155 & 338 \\
\hline & Electricity & $15 \%$ & $19 \%$ & $24 \%$ & $28 \%$ & Population & $50 \%$ & $29 \%$ & $12 \%$ & $0 \%$ \\
\hline & Diesel \& Gasoline & $78 \%$ & $71 \%$ & $63 \%$ & $55 \%$ & Urbanization & $4 \%$ & $3 \%$ & $3 \%$ & $3 \%$ \\
\hline & Natural Gas & $2 \%$ & $4 \%$ & $7 \%$ & $11 \%$ & Electrification & $0 \%$ & $0 \%$ & $0 \%$ & $0 \%$ \\
\hline & LPG & $4 \%$ & $4 \%$ & $4 \%$ & $4 \%$ & GDP per capita & $47 \%$ & $67 \%$ & $83 \%$ & $93 \%$ \\
\hline & Charcoal & $1 \%$ & $1 \%$ & $1 \%$ & $1 \%$ & Other & $0 \%$ & $1 \%$ & $2 \%$ & $4 \%$ \\
\hline & TOTAL & $100 \%$ & $100 \%$ & $100 \%$ & $100 \%$ & TOTAL & $100 \%$ & $100 \%$ & $100 \%$ & $100 \%$ \\
\hline \multirow[t]{7}{*}{ Reference Low } & TOTAL (1000 toe) & -10 & -55 & -154 & -326 & TOTAL (1000 toe) & -10 & -55 & -154 & -326 \\
\hline & Electricity & $-14 \%$ & $-19 \%$ & $-22 \%$ & $-24 \%$ & Population & $-52 \%$ & $-34 \%$ & $-19 \%$ & $-11 \%$ \\
\hline & Diesel \& Gasoline & $-79 \%$ & $-72 \%$ & $-66 \%$ & $-62 \%$ & Urbanization & $-3 \%$ & $-3 \%$ & $-2 \%$ & $-2 \%$ \\
\hline & Natural Gas & $-2 \%$ & $-4 \%$ & $-7 \%$ & $-9 \%$ & Electrification & $0 \%$ & $0 \%$ & $0 \%$ & $0 \%$ \\
\hline & LPG & $-3 \%$ & $-3 \%$ & $-3 \%$ & $-3 \%$ & GDP per capita & $-45 \%$ & $-64 \%$ & $-80 \%$ & $-90 \%$ \\
\hline & Charcoal & $-1 \%$ & $-1 \%$ & $-1 \%$ & $-1 \%$ & Other & $0 \%$ & $1 \%$ & $2 \%$ & $3 \%$ \\
\hline & TOTAL & $-100 \%$ & $-100 \%$ & $-100 \%$ & $-100 \%$ & TOTAL & $-100 \%$ & $-100 \%$ & $-100 \%$ & $-100 \%$ \\
\hline
\end{tabular}


As regards the non-residential sectors, we find that in terms of energy types, overall most of the variation in energy demand across scenarios (see Figure 6) is to be explained from differences in the consumption of electricity and transport fuels (diesel and gasoline) across scenarios. The latter are more important in the Reference High and Reference Low scenario, whereas in the Extractive scenario relatively high electricity consumption is by far the dominant factor that drives its relatively high final energy consumption path from 2020 onwards. Detailed results are presented in Table 8b.

The differences in diesel and gasoline consumption across the various Reference scenarios, as shown in Table $8 \mathrm{~b}$, are mainly caused by differences in vehicle ownership across scenarios. The outstanding role of electricity consumption in the Extractive scenario is caused by the expansion of Mozal's production capacity in 2019. The right-hand side of Table $8 \mathrm{~b}$ shows the role of key socioeconomic drivers in explaining differences in aggregate energy consumption across scenarios. Clearly, the results show that differences in per capita GDP across scenarios is by far the dominant source of variation in energy demand across scenarios. This is particularly true as regards the Extractive scenario, but also in the Reference scenarios in the longer run. Of course, this result is caused by the fact in our model structure the evolution of most activity levels and intensity effects depends positively on per capita GDP (see Section 5). In the Reference scenarios, differences in population growth across scenarios also explain a relatively large share of difference in total energy demand across scenarios, especially in the short run. This result is caused by the fact that population size is the essential driving force behind the total number of vehicles, and thus the demand for transport fuels like diesel and gasoline - this corresponds with the result in left-hand side of the Table. In the long run, per capita GDP increasingly outweighs populations as the main socio-economic driving force behind differences in total energy demand across the scenarios. Finally, Table $8 \mathrm{~b}$ shows that there is no electrification effect as regards the non-residential sectors, simply because in our model electrification only impacts households; urbanization has limited impact, through its influence on LPG use.

Because of their important role in driving aggregate energy demand patterns, we continue this section by presenting some further analyses of consumption of traditional biomass and electricity. In Figure 7 we present for the two, in this respect, most opposing scenarios - Reference High and Reference Low - over time the evolution and composition of traditional biomass consumption. We do so for nonelectrified households (the upper part of the Figure) and electrified households (the bottom part of the Figure). First, the Figure clearly illustrates that by far most traditional biomass consumption is consumed by non-electrified households. This of course is an obvious result, since these are the poorest households with most limitations in terms of energy fuel substitution possibilities. Second, from the lower part of Figure 7 it can be seen that total biomass consumption by electrified households in Mozambique nevertheless will grow substantially over the next decades, for the obvious reason that the number of 
electrified households will increase as a result of population growth and electrification. Our model results an increase by a factor 3 to 4 during the period 2011 and 2030 .
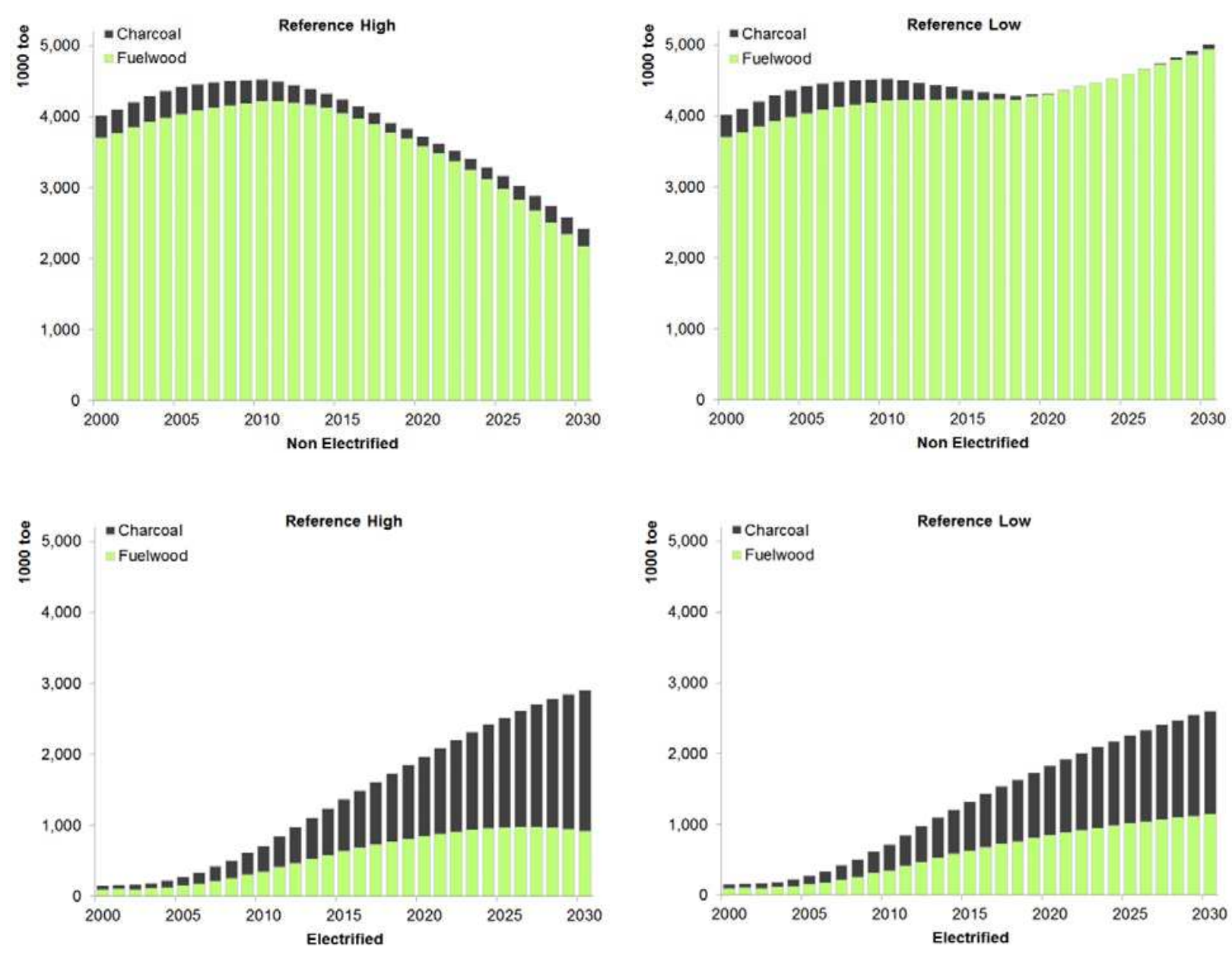

Figure 7. Biomass demand by households.

The lower part of Figure 7 plainly shows that the total increase of biomass consumption by electrified households goes together with a gradual substitution away from fuelwood towards charcoal; under influence of a higher per capita GDP this process is of course relatively fast in the Reference High scenario as compared to the Reference Low scenario. The share of charcoal is expected to increase from about $35 \%$ in 2000 to $50-60 \%$ in 2030. Fourth, the upper part of Figure 7 shows that the story is different for non-electrified households. Total biomass consumption by non-electrified households in Mozambique will continue to grow in the Reference Low scenario, but will fall relatively rapidly in the Reference High scenario. Again, the obvious reason is that the number of non-electrified households will increase in the former scenario and decrease in the latter scenario as a result of population growth and electrification. Furthermore, the Figure shows that in both scenarios the patterns of substitution of charcoal for fuelwood is $\mathrm{N}$-shaped, meaning that the relative share of charcoal consumption by these households first increases 
and then decreases, only to start to increase in the very long run. This particular pattern is to be explained from the fact that our integrated biomass model assumes that the share of charcoal consumption depends positively on levels of per capita GDP and urbanization (see section 5). Evidently, non-electrified households experience increasing per capita GDP, but at the same time are increasingly to be found in (remote) rural areas. The upper part of Figure 7 shows that the first effect dominates the latter in the short run, while the opposite is true in the long run. Only to the very end of our scenario period the first effect tends to regain the upper hand again.

We conclude this section by taking a closer look to the evolution of electricity consumption over time. As noted before, under influence of economic growth, electrification and extractive industry expansion, the demand for electricity in Mozambique has grown rapidly since 2000 and is expected to continue doing so for the time to come. In section 5 we documented that, depending on the scenario, the capacity for electricity production is expected to double or triple in the period until 2030, of which roughly half was meant to serve electricity demand from neighboring countries. In Figure 8 we illustrate this development from a demand-side perspective, showing only the Reference and Extractive scenarios because of their distinct patterns.
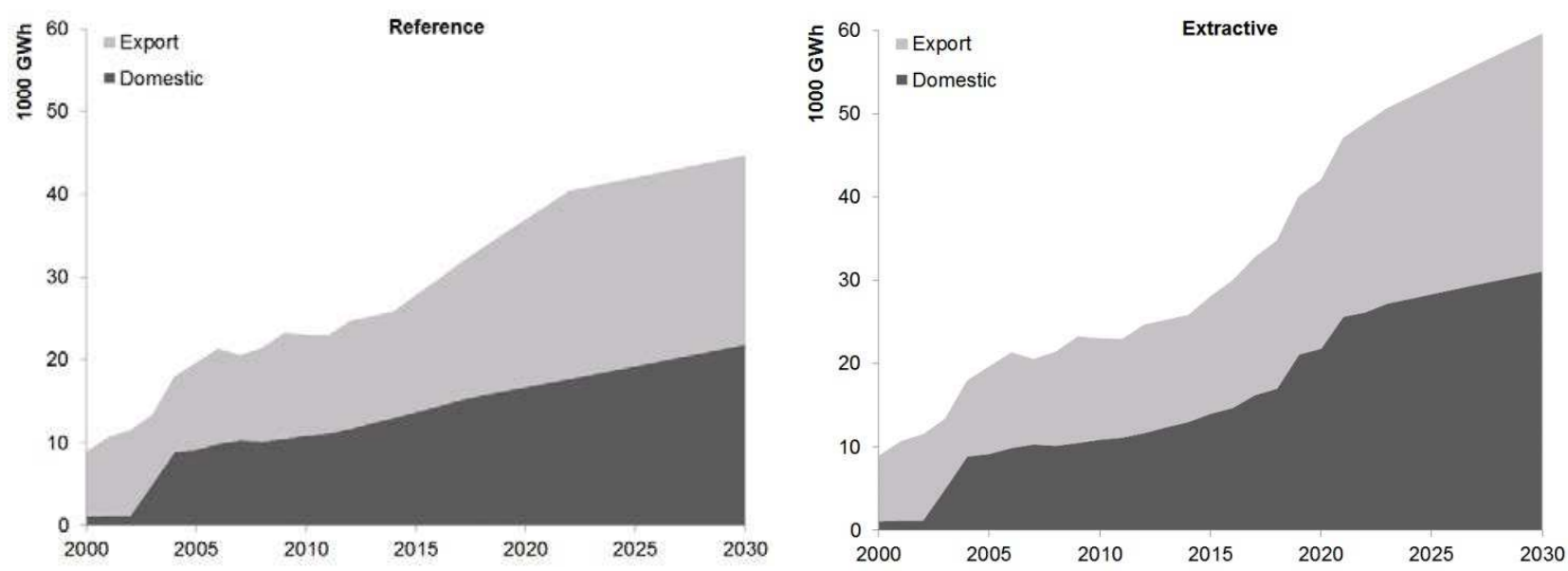

Figure 8. Electricity demand - domestic use vs exports.

Until the arrival of the Mozal aluminum smelter in 2002, almost 90\% of demand for electricity produced in Mozambique originated from neighboring countries, mainly South Africa and Zimbabwe. Figure 8 also shows that from then onwards export and domestic demand each make up for roughly half of the total demand for electricity produced in Mozambique. Recall that in our model, electricity demand from neighboring countries is mainly driven by our assumptions as regards exogenous demand from South Africa (see section 5). In sum, electricity exports are estimated to reach approximately 22-28 thousand 
GWh by 2030, depending on the scenario. Figure 8 confirms that, in spite of the expected huge increase in domestic electricity demand between 2000 and 2030, neighboring countries thus remain to be key consumers of electricity produced in Mozambique. Of course, this development depends crucially on the planned expansion of generation capacity as described in section 5 .

As regards domestic consumption of electricity demand, our model results lead us to expect for the various Reference scenarios roughly a doubling in demand from just over 11 thousand GWh in 2011 to about 20 thousand GWh in 2030. In the Extractive scenario we expect for the same period almost a tripling of electricity demand to about 31 thousand GWh. The breakdown of domestic electricity demand, as presented in Figure 9, leads to various important observations. First, the aluminum smelter (MOZAL) continues to dominate the picture of national electricity consumption. In 2010, MOZAL consumed about three quarters (equivalent to approx. 8.2 thousand GWh) of total electricity demand in Mozambique; in the Extractive scenario Mozal is expected to expand its production capacity around 2020 as a result of which its electricity demand will increase with about $30 \%$ to 10.6 thousand GWh. Second, the extractive industry sector is expected to become the second most important player in the domestic market for electricity, especially in the Extractive scenario. We expect electricity consumption from this sector to grow by 2030 to a level of 2.3 thousand GWh in the Reference scenario and 8.5 thousand GWh in the Extractive scenario - most notably because of heavy sands mining. Third, Figure 9 shows an accelerated electricity demand by manufacturing and households, while the demand trend by the other sectors (Services, Government, Agriculture and other) is more gradual. By 2030, in the Reference scenario total electricity demand by both the Residential and Manufacturing sector (excluding Mozal) is expected to grow to just over 4 thousand GWh, which equals a 5 to 6-fold increase since 2010.
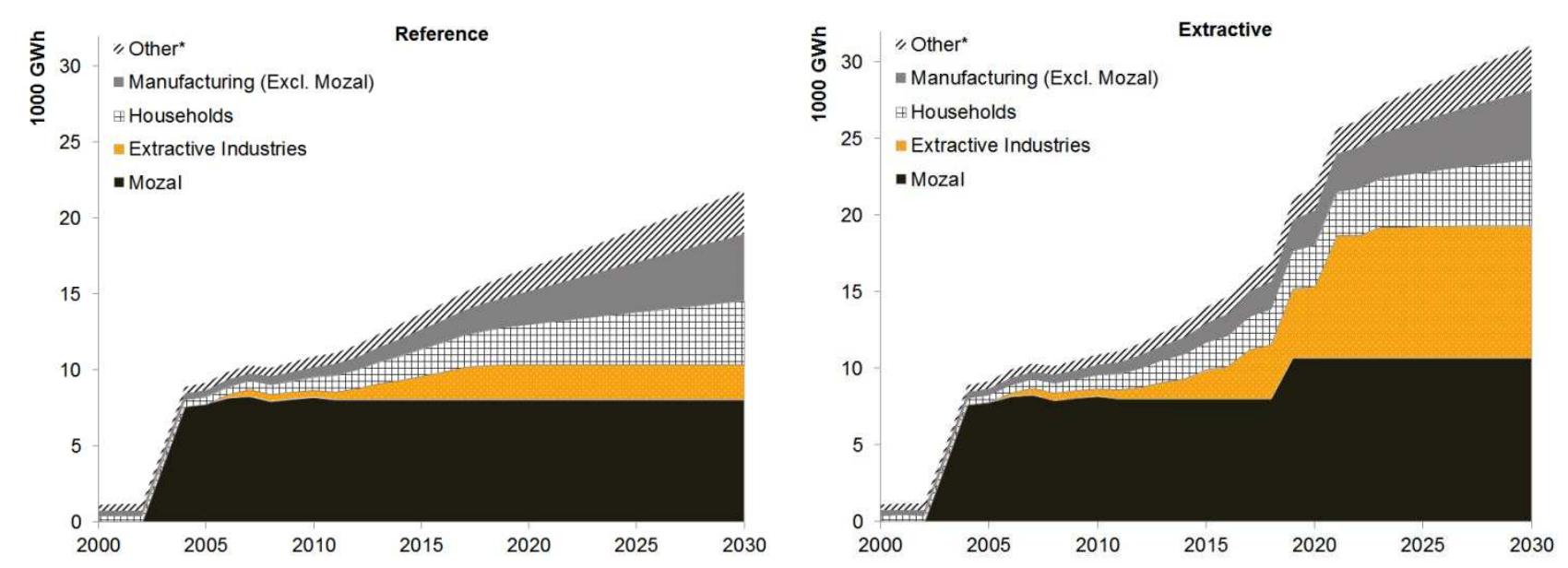

Figure 9. National demand for electricity by sectors. 


\section{Conclusions and policy implications}

In this paper we have presented the first comprehensive long-run Energy Outlook for Mozambique. Over the last years Mozambique's natural resource wealth has attracted substantial foreign direct investments in large energy-intensive industries as well as in the mining, exploration and transformation sectors. As a result, Mozambique is now rapidly developing into important player in regional and global energy markets. Our Energy Outlook is based on a newly developed scenario model, which is calibrated by means of recently developed local energy statistics and international data for the recent past, as well as on information about the latest developments and future plans as regards the production and transformation of energy in Mozambique. We have developed four scenarios to evaluate the impact of the anticipated surge in natural resources exploration on energy supply and demand in Mozambique. In addition to Reference scenarios, that describe the most likely development path in three variants (medium, high and low), we developed a scenario that assumes exploitation of Mozambique's natural resources wealth to its fullest potential.

Perhaps the most outstanding result of our analysis is the emerging 'energy-dichotomy' in Mozambique. On the one hand, the energy sector is characterized by a rapid and huge expansion, driven by sizable investments in large energy-intensive industries as well as in the mining, exploration and transformation sectors. We conclude that until 2030 primary energy production is likely to increase sixfold in the Reference scenarios and up to 13-fold in the Extractive scenario. Furthermore, we have shown that $80-90 \%$ of future energy production in Mozambique is expected to be destined for export. This is especially true for the natural gas and coal production, but to a lesser extent also for hydro-electricity. As a consequence, Mozambique is rapidly developing into an important player at international energy markets. Roughly half of the total future demand for electricity produced in Mozambique will come from the Southern African regional electricity market.

On the other hand, our analysis has shown that by 2030 the residential sector still accounts for the major part of total energy consumption in Mozambique, with large parts of the population still depending on traditional biomass to meet their energy needs. Having said that, increasing per capita income and urbanization are expected to incur a shift away from fuelwood to charcoal - we show that by 2030 charcoal may just overtake fuelwood as the major form of traditional biomass. Mozambique has one of the lowest electrification rate in the region, with about $20 \%$ total access and only 5\% of rural access (IEA, World Energy Outlook 2013, this study). We have shown that, given continued population growth, persistent electrification efforts will cause the electrification rate to increase to around $40 \%$ by 2030 which would be a major achievement but also implies that by 2030 the majority of the Mozambican population is still deprived from access to electricity. Together with the underdevelopment of the nonextractive sectors, this implies that large energy-intensive and extractive companies will continue to dominate the domestic electricity market in Mozambique. However, in terms of total energy demand, we 
conclude that until 2030 population growth continues to be a key driver of growth in energy consumption in Mozambique, to be outweighed by per capita GDP as driving force only in the long run.

In short, these findings mean that a major challenge for energy policy in Mozambique is to address this 'energy-dichotomy' by developing its large reserves of hydropower, coal, mineral sands and natural gas in such a way that it benefits its growing population as well as the non-extractive sectors of its economy. Obviously, an important strategy to do so is improving access to modern energy types by the Mozambican population. One option is careful planning of electricity transmission infrastructures providing power to mega projects in energy-intensive or extractive industries, such that required investments in (long-distance) transmission lines - that serve as important backbones for extending and reinforcing the national grid - also benefit rural electrification projects in remote areas. As one of us has argued before, the success of (rural) electrification programs would be greatly enhanced when investments in electricity infrastructure are not made in isolation but integrated with investments in complimentary infrastructures, including road, water, telecommunication and financial networks (Mulder and Tembe, 2008). Another option to address the 'energy-dichotomy' in Mozambique is to design the production and distribution of natural gas in such a way that access to LPG for residential use is not any longer limited to the better-off households in a few major urban areas.

Finally, we note that the Mozambican energy sector increasingly becomes sensitive to climate variability. Our analysis has shown that, although natural gas and coal are likely to play a dominant role in the future energy supply mix, hydro will account for between $60-80 \%$ of total electricity production. This hydro capacity is mostly generated from the Zambezi Basin. We have shown that, as a result of these and other projects the total electricity production level is planned to increase at least two-fold over the next decades. Recent studies conducted on the Zambezi River Basin suggest that the potential risk of climate change is considerable, and consists of draughts that reduce run-off and reservoir storage capacity as well as increasing frequency and severity of floods that may lead to shutdowns and damage of hydro power stations and the downstream transmission network (Yamba et al 2011). Hence, also in this respect, appropriate institutional frameworks and economic incentives are required to benefit in a sustainable way from the rapid change and growth of the country's energy sector. Of course, this is much more easily said than done. 


\section{REFERENCES}

Aburas, R., 1993. Jordan's energy outlook. Energy Policy 21, 152-157.

Ahlborg, H., Hammar, L., 2014. Drivers and barriers to rural electrification in Tanzania and Mozambique e Grid-extension, off-grid, and renewable energy technologies. Renewable Energy 61, 117 -124.

Arndt, C., Benfica, R., Tarp, F., Thurlow, J., Uaiene, R., 2010. Biofuels, poverty, and growth: a computable general equilibrium analysis of Mozambique. Environment and Development Economics $15,81-105$.

Arndt, C., Benfica, R., Thurlow, J., 2011. Gender Implications of Biofuels Expansion in Africa: The Case of Mozambique. World Development 39, 1649-1662.

Arthur, M. F.S.R., Zahran, S., Bucini, G., 2010. On the adoption of electricity as a domestic source by Mozambican households. Energy Policy 38, 7235-7249.

Arthur, M.F.S.R., Bond, C. A., Willson, B., 2012. Estimation of elasticities for domestic energy demand in Mozambique. Energy Economics 34, 398-409.

Atanassov, B., Egas, A., Falcão, M., Fernandes, A., Mahumane, G., 2012. Mozambique urban biomass energy analysis: Maputo, Matola, Beira and Nampula. Ministry of Energy. Maputo, Mozambique.

Barnes, D.F., Floor, W., 1999. Biomass energy and the poor in the developing countries. Journal of International Affairs 53, 237-259.

Barnes, D.F., Krutilla, K., Hyde, W., 2005. The Urban Household Energy Transition; Energy, Poverty, and the Environment in the Developing World. Washington, DC: World Bank.

Batidzirai, B., Faaij, A., Smeets, E., 2006. Biomass and bioenergy supply from Mozambique. Energy for Sustainable Development X, 54-81.

Bhattacharyya, S. C., 2010. Shaping a sustainable energy future for India: Management challenges. Energy Policy 38, $4173-4185$.

Bleiwas, D.I., 2011. Estimates of electricity requirements for the recovery of mineral commodities, with examples applied to sub-Saharan Africa. U.S. Geological Survey Open-File Report 2011-1253, 100 p.

BM (Banco de Moçambique), 2011. Balança de Pagamentos, $N^{\circ}$ 08, Ano 08. Maputo, Mozambique.

Boom, B., 2011. Analysis of poverty in Mozambique: household poverty status, child malnutrition and other indicators 1997, 2003, 2009. SOW-VU, Centre for World Food Studies, VU University, Amsterdam, the Netherlands.

BP, 2012. BP Statistical Review of World Energy, June 2012. London SW1Y 4PD, UK.

Brouwer, R., Falcão, M., 2004. Wood fuel consumption in Maputo, Mozambique. Biomass and Bioenergy $27,233-245$. 
Bucuane, A., Mulder, P., 2009b. Expanding exploitation of natural resources in Mozambique: will it be a blessing or a curse?, in: Brito, L. de, C. Castel-Branco, S. Chichava and A. Fransisco (eds.), Reflecting on Economic Questions. IESE, 2009, pp. 104-153. Maputo, Mozambique.

Button, K., Ngoe, N., Hine, J. 1993. Modeling Vehicle Ownership and Use in Low Income Countries. Journal of Transport Economics and Policy, 51-67.

Cuvilas, C.A., Jirjis, R., Lucas, C., 2010. Energy situation in Mozambique: A review. Renewable and Sustainable Energy Reviews 14, 2139-2146.

Di Lucia, L., 2010. External governance and the EU policy for sustainable biofuels, the case of Mozambique. Energy Policy 38, 7395-7403

Ecoenergy, 2008. Mozambique Biofuels Assessment, final report released in May, 2008. The Ministry of Agriculture and the Ministry of Energy. Maputo Mozambique.

EdM (Electrididade de Moçambique), 2004. Mozambique Electricity Master Plan Study, Final Master Plan Report, November 2004. EdM / Norconsult -SwedPower. Maputo, Mozambique.

Hatton, W. and Fardell, A., 2012. New discoveries of coal in Mozambique - Development of the coal resource estimation methodology for International Resource Reporting Standards. International Journal of Coal Geology 89, 2 -12.

Heaps, C.G., 2012. Long-range Energy Alternatives Planning (LEAP) system. [Software version 2014.0.1.18] Stockholm Environment Institute. Somerville, MA, USA. www.energycommunity.org.

IEA, 2013a. World Energy Outlook 2013. Paris: International Energy Agency.

IEA, 2013b. Energy Prices and Taxes. Quarterly Statistics, Fourth quarter, 2013. Paris: International Energy Agency

IEA, 2014. IEA Africa Energy Outlook. Paris: International Energy Agency.

IMF, 2013. Republic of Mozambique. IMF Country Report No. 13/200, July 2013. International Monetary Fund, Washington, D.C.

INATTER (Instituto Nacional dos Trasportes Terrestres), 2012. Ministério Dos Transportes e Comunicações. Maputo, Mozambique. http://www.inatter.gov.mz/.

INE (Instituto Nacional de Estatística), 2009. Relatório final do Inquérito de Indicadores Múltiplos (MICS) 2008. Maputo, Mozambique.

INE (Instituto Nacional de Estatística), 2010a. Inquérito sobre Orçamento Familiar (IOF) 2008/2009. Maputo, Mozambique.

INE (Instituto Nacional de Estatística), 2010b. Base de Dados do Censo 2007, http://www.ine.gov.mz/. Maputo, Mozambique.

IRENA (International Renewable Energy Agency), 2012. Mozambique: Renewables readiness assessment 2012. Report released in November, 2012. 
Kibune, H., Kudo, H., 1996. Structural changes in Japan's economy and society and outlook for long-term energy supply and demand. Energy Policy 24, 1119 - 1125.

Kim, S. H, Kim, T. H., Kim, Y., Na, I. Gang., 2000. Korean energy demand in the new millennium: outlook and policy implications, 2000 - 2005. Energy Policy 29, 899 - 910.

KPMG, 2013. Mining Mozambique: Country mining guide. KPMG International, publication № 130547.

Leach, G., 1992.The Energy Transition. Energy Policy 20, 116-123.

Lescaroux, F. 2011. Dynamics of final sectoral energy demand and aggregate energy intensity. Energy Policy 39, 66-82.

McPherson, M., Karney, B., 2014. Long-term scenario alternatives and their implications: LEAP model application of Panama's electricity sector. Energy Policy 68, 146-157.

ME (Ministry of Energy), 2012. Energy Statistics, 2000 - 2011. Direcção de Estudos e Planificação Maputo, Mozambique.

Mahumane, G., Mulder, P. (2015). Introducing MOZLEAP: an integrated long-run scenario model of the emerging energy sector of Mozambique. VU Amsterdam Research Memorandum , RM 2015-2 .

Medlock, K.B., Soligo, R., 2002. Automobile Ownership and Economic Development: Forecasting Passenger Vehicle Demand to the year 2015. Journal of Transport Economics and Policy 36, 163-188.

Ministry of Energy, 2009. Generation master plan for the Mozambican power sector, Final Report, July 2009. Norconsult/ Ministry of Energy. Maputo, Mozambique.

Mulder, P., 2007. Energy Outlook for Mozambique. Ministry of Planning and Development, Discussion Paper No.53E. Maputo, Mozambique.

Mulder, P., Tembe, J., 2008. Rural electrification in an imperfect world: A case study from Mozambique. Energy Policy 36, 2785- 2794.

Nhete, T. D., 2007. Electricity sector reform in Mozambique: projection into the poverty and social impacts. Journal of Cleaner Production 15, 190 - 202.

Norconsult, 2011. Mozambique Regional Transmission Backbone Project (CESUL): Technical and Economic Feasibility Study, CESUL Launch Workshop. Presentation held on 24 November 2011 at Centro de Conferências Joaquim Chissano. Maputo, Mozambique.

Pereira Jr., A. O., Soares, J. B., Oliveira, R. G., Queiroz, R. P., 2008. Energy in Brazil: Toward sustainable development? Energy Policy 36, 73-83.

SA Department of Energy, 2011. Integrated Resource Plan for Electricity (IRP) 2010-2030, Final Report, March, 2011. Republic of South Africa.

Schut, M., Slingerland, M., Locke, A., 2010. Biofuel developments in Mozambique. Update and analysis of policy, potential and reality. Energy Policy 38, 5151-5165.

Schut, M., Soares, N. S., van de Ven, G., Slingerland, M., 2014. Multi-actor governance of sustainable biofuels in developing countries: The case of Mozambique. Energy Policy 65, 631-643. 
Sebitosi, A. B., da Graça, A., 2009. Cahora Bassa and Tete Province (Mozambique): A great potential for an industrial hub in Southern Africa. Energy Policy 37, 2027-2032.

SEE (Sustainability Consulting), 2009. Ulan Coal Continued Operations Project, Scope 1, 2 \& 3 Energy \& Greenhouse Assessment. Ulan Coal Limited.

Solomon, B. D., Krishna, K., 2011. The coming sustainable energy transition: History, strategies, and outlook. Energy Policy 39, 7422-7431.

UN, 2008. World Urbanization Prospects; The 2007 Revision. New York: United Nations

Yager, T. R., 2012. The Mineral Industry of Mozambique. U.S. Geological Survey Minerals Yearbook, 2012.

Yamashita, Y., Ishida, H., 2000. Japan's short-term energy outlook - FY1998 records and short-term forecast up to FY2000. Energy Policy 28, 799 - 814.

Yamba, F. D., Walimwipi, H., Jain, S., Zhou, P., Cuamba, B., Mzezewa, C., 2011. Climate change/ variability implications on hydroelectricity generation in the Zambezi River Basin. Mitig Adapt Strateg Glob Change 16, 617-628.

Zachariadis, T., 2011. Medium-term energy outlook for Cyprus and its policy implications. Energy Policy 39, 6631-6635.

Zhou, N., Fridley, D., Khanna, N. Z., Ke, J., McNeil, M., Levine. M., 2013. China's energy and emissions outlook to 2050: Perspectives from bottom-up energy end-use model. Energy Policy 53, 51-62. 


\section{ANNEX A}

Our scenario model includes three separate modelling components to model, respectively, the development paths of GDP, biomass and transport fuel consumption - these components are embedded in LEAP's overall accounting framework. Their structure and calibration is as follows.

\section{GDP model}

We start with historical data on Mozambique's total GDP and its sector structure for the period 20002010. From these data series we derive historical GDP growth rates, excluding the extractive sector - we label this baseline GDP growth. Subsequently, adopting a simple top-down approach, for the period 20112030 we assume that baseline GDP growth $Y$ follows a declining trend as function of time $t$, according to the following straightforward logistic curve,

$$
Y_{t}=Y_{t-1} \mathrm{e}^{-\delta t}
$$

with $\delta$ a parameter that determines the speed of decline in the logistic curve. During the period 2000-2010 Mozambique experienced rapid economic growth, on average $7.3 \%$ per year for total GDP and 5.5\% for per capita GDP. The value of $\delta$ in equation (1) is scenario-specific and chosen such that annual GDP growth gradually evolves towards $3.8 \%-5.9 \%$ by 2030 , depending on the scenario (see Table A.2). Next, using a bottom-up approach, we construct GDP separately for each extractive industry, as described in section 5 of the paper. Together with the baseline GDP this sums up to total GDP, including an implied total GDP growth rate. Finally, we construct a sectoral breakdown of aggregate GDP by calculating future sector shares of four main sectors (agriculture, services, manufacturing and government) as percentage of total GDP. Again, our starting point is historical data for the period 2000-2011 from existing sources. Next, we assume that the respective sector shares $S$ evolve over time as a function of per capita GDP $y$, according to the following logistic curve:

$$
S_{(t)}=S_{t-1} *\left[1+\frac{\Theta}{\mathrm{y}_{t}}\right]^{\Delta \mathrm{y}_{t}}
$$

with parameter $\theta$ signifying the elasticity of the change in the sectoral composition of the economy under influence of economic development. The value of $\theta$ is sector-specific and is derived from cross-country regressions of the relation between per capita GDP and the respective sector share, using Worldbank data for 39 countries with per capita GDP values between US\$700 and US\$3000; estimated coefficients vary from -2.94 for agriculture to 4.86 for manufacturing (see Table A.4). 


\section{Biomass model}

We adopt a nested model structure. First, we assume that total biomass consumption is merely determined by GDP per capita, thus considering substitution with modern energy forms (such as LPG and electricity) as function of relative prices a second-order effect. Second, we assume that the choice for one of the two dominant forms of biomass (fuelwood and charcoal) is implicitly driven by their relative prices as well as the urbanization rate. More specifically, we first define the evolution of per capita biomass consumption $B$ over time $t$ according to a logarithmic S-shaped curve, as follows:

$$
B_{t}=\alpha\left[1+\beta \mathrm{e}^{-\gamma y_{t}}\right] \text {, }
$$

where $\alpha$ is the initial value of B (in the year 2000), $\beta$ is a constant (vertical shift of the curve ), and $\gamma$ the elasticity of $B$ with respect to GDP per capita $y$. The value for $\alpha$ is estimated on the basis of a combination of international data (IEA Energy Balances 2010) and local household survey data (Atanassov, et. al., 2012; INE, 2009), and equals 10.5 GJ per capita. The values for $\beta$ and $\gamma$ are derived from a cross-country logarithmic panel data regression of biomass consumption on per capita GDP for the period 1971-2006, using IEA data for 74 countries with per capita values below US\$3000; estimated coefficients for $\beta$ and $\gamma$ equal 0.0274 and 0.239 , respectively (see Table A.4). ${ }^{9}$ Next, we define the evolution of per capita consumption of charcoal $C$ and fuelwood $F$ as follows:

$$
\begin{aligned}
& C_{t}=B_{t} \lambda_{t} \quad \text { with } \lambda_{t}=\lambda_{t-1}[(1+\rho) \gamma] \\
& F_{t}=B_{t}\left[1-\lambda_{t}\right]
\end{aligned}
$$

where $\lambda$ is the share of charcoal in total biomass consumption, $\rho$ is the inter-fuel substitution elasticity (i.e. between charcoal and fuelwood) and $\gamma$ is the annual growth rate urbanization. Historical values for $\gamma$ were derived from census data (INE, 2010b), whereas values for $\lambda$ in the initial year (2000) and $\rho$ were derived from local household survey data (Atanassov et. al., 2012; INE, 2009), with $\rho$ set at 0.03. Future values for $\gamma$ are taken from expected urbanization trends published by the UN in its World Urbanization Prospects (UN 2008). Finally, to allocate charcoal and fuelwood consumption across electrified and non-electrified households, we first assume that in 2000 all electrified households lived in urban areas, and that in 2011 the urban and rural electrification rates were, respectively 55\% and 5\% (IEA 2013). Second, we assume that $5 \%$ of total fuelwood consumption and $85 \%$ of total charcoal consumption is consumed by urban households with the remainder being consumed by rural households (Atanassov, et. al., 2012; Brouwer and Falcão, 2004; INE, 2009). Third, we assume that fuelwood and charcoal is consumed by, respectively,

\footnotetext{
${ }^{9}$ The US\$3000 cut-off criterion is chosen to avoid a potential bias in the estimated coefficients: the share of biomass in total energy consumption becomes in general very low in countries where GDP per capita exceeds US\$3000; in our scenarios per capita GDP increases from about US\$ 400 in 2010 to around US\$1000 by 2030.
} 
$33 \%$ and $80 \%$ of households in urban areas, while $10 \%$ of households in rural areas consume charcoal. ${ }^{10}$ Finally, building on these assumptions we model future evolution of biomass consumption per electrified household $b_{t}^{\text {Elec }}$ as a function of changes in the total biomass consumption (equations 3-5) as well as the change in urbanization rate $U$ relative to the change in the electrification rate $E$, according to

$$
b_{t}^{E l e c}=\Delta b_{t-1}\left[1+\frac{\Delta U}{\Delta E}\right]
$$

with $b$ representing either charcoal $C$ or fuelwood $F$ per electrified household. Biomass intensity per nonelectrified household is subsequently derived from total biomass consumption not consumed by electrified households.

\section{Fuel consumption model}

We model fuel demand for road transport as function of vehicle ownership over time, given the evolution of per capita GDP and population. We assume the number of vehicles per 1000 people to be merely determined by GDP per capita, thus considering (relative) fuel prices a second-order effect. More specifically, we define the number of vehicles $V$ per 1000 people at time $t$ according to:

$$
V_{t}=V_{t-1} *\left[1+\frac{\psi}{\mathrm{y}_{t}}\right]^{\Delta \mathrm{y}_{t}}
$$

with parameter $\psi$ denoting the elasticity of the change in vehicle ownership under influence of economic development. The value of $\psi$ is derived from a cross-country logarithmic panel data regression of passenger car ownership on per capita GDP for the period 1971-2006, using data from the Worldbank Indicators database for 74 countries with per capita values below US\$3000; the estimated coefficient for $\psi$ equals 8.7 (see Table A.4). In the absence of more detailed data we assume this parameter to apply equally to the evolution of passenger cars as well as trucks, motorcycles and tractors. We calibrate this function on the basis of data on the annual evolution of registered vehicles in Mozambique and fuel consumption in the recent past, supplied by, respectively, the Mozambican National Institute of Road Transport (INATTER, 2012) and the Ministry of Energy (ME, 2012).

\footnotetext{
${ }^{10}$ Note that rural electrification has a minor impact on switching of cooking fuel while the opposite is true for urbanization, which is a major driving force for the choice of cooking fuel.
} 


\section{ANNEX B}

Table A.1 The structure of the MOZLEAP modelling framework.

\begin{tabular}{|c|c|c|c|}
\hline Category, Sector & Subsector & Activity & Energy type \\
\hline \multicolumn{4}{|l|}{ DEMAND } \\
\hline \multirow[t]{2}{*}{ Residential } & Electrified & \# Households & $\begin{array}{l}\text { Electricity, LPG, Kerosene, Charcoal, } \\
\text { Fuelwood }\end{array}$ \\
\hline & Non Electrified & \# Households & Kerosene, Charcoal, Fuelwood \\
\hline Agriculture & & & Electricity, Diesel \\
\hline Manufacturing & $\begin{array}{l}\text { MOZAL } \\
\text { Other Industry }\end{array}$ & $\begin{array}{l}\text { Metric Tonne } \\
\text { GDP }\end{array}$ & $\begin{array}{l}\text { Fuel Oil, Natural Gas, Electricity } \\
\text { Fuel Oil, Natural Gas, Electricity, Diesel }\end{array}$ \\
\hline Services & $\begin{array}{l}\text { Commercial Services } \\
\text { Public Lighting }\end{array}$ & $\begin{array}{l}\text { GDP } \\
\text { Not applicable }\end{array}$ & $\begin{array}{l}\text { Electricity, LPG, Fuelwood, Charcoal } \\
\text { Electricity }\end{array}$ \\
\hline Government & & GDP & Electricity \\
\hline \multirow[t]{2}{*}{ Extractive Industries } & $\begin{array}{l}\text { Coal Mining* } \\
\text { Natural Gas } \\
\text { Exploration }\end{array}$ & $\begin{array}{l}\text { Metric Tonne } \\
\text { GDP }\end{array}$ & $\begin{array}{l}\text { Electricity, Diesel } \\
\text { Natural Gas }\end{array}$ \\
\hline & Heavy Sands Mining* & $\begin{array}{l}\text { Metric Tonne } \\
\text { GDP }\end{array}$ & $\begin{array}{l}\text { Electricity, Diesel } \\
\text { Electricity }\end{array}$ \\
\hline \multirow[t]{4}{*}{ Transport Road } & Passenger Cars & \# Vehicles & Gasoline, Ethanol \\
\hline & Trucks & \# Vehicles & Diesel, Methanol \\
\hline & Motorcycles & \# Vehicles & Gasoline, Ethanol \\
\hline & Tractors & \# Vehicles & Diesel, Methanol \\
\hline \multirow[t]{3}{*}{ Regional Electricity Demand } & South Africa & Not applicable & Electricity \\
\hline & Zimbabwe & Not applicable & Electricity \\
\hline & Other & Not applicable & Electricity \\
\hline \multicolumn{4}{|l|}{ STATISTICAL DIFFERENCES } \\
\hline & Primary & & All primary \\
\hline & Secondary & & All secondary \\
\hline \multicolumn{4}{|l|}{ TRANSFORMATION } \\
\hline Transmission and Distribution & & & Electricity, Natural Gas \\
\hline \multirow[t]{4}{*}{ Electricity Generation } & Solar PV & & Electricity \\
\hline & Hydro & & Electricity \\
\hline & Thermal Natural Gas & & Electricity \\
\hline & Thermal Coal & & Electricity \\
\hline \multirow[t]{2}{*}{ Charcoal Making } & Existing & & Charcoal \\
\hline & New Efficient & & Charcoal \\
\hline Coal Mining & & & Coal \\
\hline Natural Gas Exploration & & & Natural Gas \\
\hline \multicolumn{4}{|l|}{ STOCK CHANGES } \\
\hline & Primary & & All primary \\
\hline & Secondary & & All secondary \\
\hline \multicolumn{4}{|l|}{ RESOURCES } \\
\hline & Primary & & All primary \\
\hline & Secondary & & All secondary \\
\hline
\end{tabular}




\begin{tabular}{|c|c|c|c|c|c|c|c|c|c|c|c|c|c|c|c|c|c|c|}
\hline & \multirow[b]{3}{*}{ Unit } & \multirow[b]{3}{*}{2010} & \multicolumn{12}{|c|}{ Reference } & \multicolumn{4}{|c|}{ Extractive } \\
\hline & & & \multicolumn{4}{|c|}{ Medium } & \multicolumn{4}{|c|}{ Low } & \multicolumn{4}{|c|}{ High } & & & & \\
\hline & & & 2015 & 2020 & 2025 & 2030 & 2015 & 2020 & 2025 & 2030 & 2015 & 2020 & 2025 & 2030 & 2015 & 2020 & 2025 & 2030 \\
\hline \multicolumn{19}{|l|}{ GDP } \\
\hline Parameter $\delta$ & $1 / 100$ & -- & 0.2 & 0.2 & 0.2 & 0.2 & 0.3 & 0.3 & 0.3 & 0.3 & 0.1 & 0.1 & 0.1 & 0.1 & 0.1 & 0.1 & 0.1 & 0.1 \\
\hline \multicolumn{19}{|l|}{ Unit price change } \\
\hline Natural Gas & $\%$ & -- & 0.0 & 2.0 & 2.0 & 2.0 & 0.0 & 0.0 & 0.0 & 0.0 & 0.0 & 4.0 & 4.0 & 4.0 & 0.0 & 4.0 & 4.0 & 4.0 \\
\hline Heavy Sands & $\%$ & -- & 0.0 & 0.0 & 0.0 & 0.0 & -1.0 & -1.0 & -1.0 & -1.0 & 1.0 & 1.0 & 1.0 & 1.0 & 1.0 & 1.0 & 1.0 & 1.0 \\
\hline Coal & $\%$ & -- & -1.0 & 0.0 & 0.0 & 0.0 & -1.0 & -2.0 & -2.0 & -2.0 & -1.0 & 2.0 & 2.0 & 2.0 & -1.0 & 2.0 & 2.0 & 2.0 \\
\hline Aluminum & $\%$ & -- & 0.0 & 0.0 & 0.0 & 0.0 & -1.0 & -1.0 & -1.0 & -1.0 & 1.0 & 1.0 & 1.0 & 1.0 & 1.0 & 1.0 & 1.0 & 1.0 \\
\hline \multicolumn{19}{|l|}{ Population } \\
\hline Growth population & $\%$ & 2,45 & 2,36 & 2,25 & 2,13 & 2,01 & 2,60 & 2,64 & 2,56 & 2,43 & 2,14 & 1,88 & 1,70 & 1,57 & 2,14 & 1,88 & 1,70 & 1,57 \\
\hline Growth urban population & $\%$ & 3,23 & 3,39 & 3,50 & 3,50 & 3,45 & 1,69 & 1,75 & 1,75 & 1,73 & 5,08 & 5,25 & 5,26 & 5,18 & 5,08 & 5,25 & 5,26 & 5,18 \\
\hline Household size & $\#$ & 4,33 & 4,29 & 4,26 & 4,22 & 4,19 & 4,30 & 4,29 & 4,27 & 4,25 & 4,28 & 4,23 & 4,18 & 4,13 & 4,28 & 4,23 & 4,18 & 4,13 \\
\hline \multicolumn{19}{|l|}{ Electricity distribution } \\
\hline \# New connections / year & 1000 & 110 & 135 & 123 & 112 & 100 & 129 & 109 & 90 & 70 & 141 & 137 & 134 & 130 & 135 & 123 & 112 & 100 \\
\hline Losses* & $\%$ & 5.0 & 5.0 & 5.0 & 5.0 & 5.0 & 5.0 & 5.0 & 5.0 & 5.0 & 5.0 & 5.0 & 5.0 & 5.0 & 5.0 & 5.0 & 5.0 & 5.0 \\
\hline
\end{tabular}

$\delta$ : Speed of decline logistic curve of baseline GDP growth

* Transformation and distribution losses 
Table A.3 Key parameter values Energy Intensity Builder

\begin{tabular}{|c|c|c|c|}
\hline Sector & Fuel type & Characterization & Value or formula \\
\hline \multirow[t]{5}{*}{ Residential } & Electricity & Increase & $\mathrm{I}_{\mathrm{t}}=\mathrm{I}_{\mathrm{t}-1} *\left(1+\left(0,1 * \Delta \mathrm{Y}_{\mathrm{t}}\right)\right.$ \\
\hline & LPG & Increase & $\mathrm{I}_{\mathrm{t}}=\mathrm{I}_{\mathrm{t}-1} *\left(1+\Delta \mathrm{Y}_{\mathrm{t}}\right) *\left(1+\Delta \mathrm{U}_{\mathrm{t}}\right)$ \\
\hline & Kerosene & Decrease & $-5 \%$ per year \\
\hline & Charcoal & Increase & See Biomass model \\
\hline & Fuelwood & Decrease & See Biomass model \\
\hline Agriculture & Total & Increase & 0.65 MJ/GDP (End year value 2030) \\
\hline MOZAL & Total & Constant & $55.1 \mathrm{GJ} / \mathrm{MT}$ \\
\hline Other Industry & Total & Increase & $2.4 \%$ / year in 2011, gradually towards $0 \%$ / year in 2030. \\
\hline \multirow[t]{3}{*}{ Commercial Services } & Electricity & Increase & $1 \%$ per year \\
\hline & LPG & Increase & $\mathrm{I}_{\mathrm{t}}=\mathrm{I}_{\mathrm{t}-1} *\left(1+\Delta \mathrm{Y}_{\mathrm{t}}\right) *\left(1+\Delta \mathrm{U}_{\mathrm{t}}\right)$ \\
\hline & Fuelwood, Charcoal & Decrease & $-3 \%$ per year \\
\hline Public Lighting & Electricity & Increase & $\mathrm{I}_{\mathrm{t}}=\mathrm{I}_{\mathrm{t}-1} *\left(1+\left(0,5 * \Delta \mathrm{Y}_{\mathrm{t}}\right)\right.$ \\
\hline Government & Electricity & Increase & $1 \%$ per year \\
\hline Other sectors & Electricity & Increase & $1 \%$ per year \\
\hline \multirow[t]{2}{*}{ Coal Mining } & Electricity & Constant & $27 \mathrm{kWh} / \mathrm{MT}$ \\
\hline & Diesel & Constant & 2 Liter/MT \\
\hline \multirow[t]{2}{*}{ Heavy Sands Mining } & Electricity & Constant & $600 \mathrm{kWh} / \mathrm{MT}$ \\
\hline & Diesel & Constant & 2 Liter/MT \\
\hline Tractors & Total & Increase & $\mathrm{I}_{\mathrm{t}}=\mathrm{I}_{\mathrm{t}-1} *\left(1+\left(0,05 * \Delta \mathrm{Y}_{\mathrm{t}}\right)\right.$ \\
\hline Other Vehicles & Total & Decrease & $\mathrm{I}_{\mathrm{t}}=\mathrm{I}_{\mathrm{t}-1} *\left(1+\left(-0,05 * \Delta \mathrm{Y}_{\mathrm{t}}\right)\right.$ \\
\hline
\end{tabular}

Table A.4 Estimation results for coefficients MOZLEAP model*

\begin{tabular}{lrrrrrr}
\hline & \multicolumn{3}{c}{ Sector shares } & & $\begin{array}{r}\text { Biomass } \\
\text { elasticity }\end{array}$ & $\begin{array}{r}\text { Vehicle } \\
\text { ownership }\end{array}$ \\
\cline { 2 - 7 } Constant & $\theta$ SRV & $\theta$ MAN & $\theta$ AGR & $\theta$ GOV & $\gamma$ & $\Psi$ \\
\cline { 2 - 7 } Coefficient & 46.554 & -22.577 & 37.843 & 10.009 & 1.989 & -42.752 \\
$\mathrm{R}^{2}$ & 0.834 & 4.861 & -2.935 & 0.822 & 0.239 & 8.659 \\
\# observations & 0.10 & 0.51 & 0.40 & 0.56 & 0.40 & 0.27 \\
\hline
\end{tabular}

$*$ Dep. variable $=$ coefficient $* \ln ($ GDP per capita $)+$ constant . 


\section{Research Memoranda of the Faculty of Economics and Business Administration}

2011

2011-1

Yoshifumi Takahashi Peter Nijkamp

2011-2 Paulo A.L.D. Nunes Peter Nijkamp

2011-3 Eric de Noronha Vaz Doan Nainggolan Peter Nijkamp Marco Painho

2011-4 Karima Kourtit Peter Nijkamp

2011-5 Manie Geyer Helen C. Coetzee

Danie Du Plessis

Ronnie Donaldson

Peter Nijkamp

2011-6 Aki Kangasharju Christophe Tavéra Peter Nijkamp

2011-7 Amitrajeet A. Batabyal Peter Nijkamp

2011-8 Aliye Ahu Akgün Tüzin Baycan Levent Peter Nijkamp

2011-9 Aliye Ahu Akgün Eveline van Leeuwen Peter Nijkamp

2011-10 Tibert Verhagen Jaap van Nes Frans Feldberg Willemijn van Dolen

2011-11 Henk J. Scholten Maarten van der Vlist

2011-12 Tüzin Baycan Peter Nijkamp

2011-13 Aliye Ahu Akgün Tüzin Baycan Peter Nijkamp

2011-14 Selmar Meents
Multifunctional agricultural land use in sustainable world, $25 \mathrm{p}$.

Biodiversity: Economic perspectives, $37 \mathrm{p}$.

A complex spatial systems analysis of tourism and urban sprawl in the Algarve, $23 \mathrm{p}$.

Strangers on the move. Ethnic entrepreneurs as urban change actors, $34 \mathrm{p}$.

Recent business transformation in intermediate-sized cities in South Africa, 30

p.

Regional growth and unemployment. The validity of Okun's law for the Finnish regions, $17 \mathrm{p}$.

A Schumpeterian model of entrepreneurship, innovation, and regional economic growth, $30 \mathrm{p}$.

The engine of sustainable rural development: Embeddedness of entrepreneurs in rural Turkey, $17 \mathrm{p}$.

A systemic perspective on multi-stakeholder sustainable development strategies, $26 \mathrm{p}$.

Virtual customer service agents: Using social presence and personalization to shape online service encounters, $48 \mathrm{p}$.

De inrichting van crisisbeheersing, de relatie tussen besluitvorming en informatievoorziening. Casus: Warroom project Netcentrisch werken bij Rijkswaterstaat, $23 \mathrm{p}$.

A socio-economic impact analysis of cultural diversity, $22 \mathrm{p}$.

Repositioning rural areas as promising future hot spots, $22 \mathrm{p}$.

How sellers can stimulate purchasing in electronic marketplaces: Using 
Tibert Verhagen

Paul Vlaar

2011-15

Aliye Ahu Gülümser

Tüzin Baycan-Levent

Peter Nijkamp

2011-16 Frank Bruinsma

Karima Kourtit

Peter Nijkamp

2011-17 Peter Nijkamp

Frank Bruinsma

Karima Kourtit

Eveline van Leeuwen

2011-18 Eveline van Leeuwen

Peter Nijkamp

Piet Rietveld

2011-19 Eveline van Leeuwen

Peter Nijkamp

2011-20 Aliye Ahu Akgün

Tüzin Baycan

Peter Nijkamp

2011-21 Aliye Ahu Gülümser

Tüzin Baycan-Levent

Peter Nijkamp

2011-22 Jessie Bakens

Peter Nijkamp

2011-23 Peter Nijkamp

Galit Cohen-

blankshtain

2011-24 Maura Soekijad Irene Skovgaard Smith

2011-25 Evgenia Motchenkova

Olgerd Rus

2011-26 Karima Kourtit Peter Nijkamp

2011-27 Faroek Lazrak

Peter Nijkamp

Piet Rietveld

Jan Rouwendal

2011-28 Peter Nijkamp information as a risk reduction signal, $29 \mathrm{p}$.

Measuring regional creative capacity: A literature review for rural-specific approaches, $22 \mathrm{p}$.

Tourism, culture and e-services: Evaluation of e-services packages, $30 \mathrm{p}$.

Supply of and demand for e-services in the cultural sector: Combining top-down and bottom-up perspectives, $16 \mathrm{p}$.

Climate change: From global concern to regional challenge, 17 p.

Operational advances in tourism research, $25 \mathrm{p}$.

Creative capacity for sustainable development: A comparative analysis of European and Turkish rural regions, $18 \mathrm{p}$.

Business dynamics as the source of counterurbanisation: An empirical analysis of Turkey, $18 \mathrm{p}$.

Lessons from migration impact analysis, $19 \mathrm{p}$.

Opportunities and pitfalls of local e-democracy, $17 \mathrm{p}$.

The 'lean people' in hospital change: Identity work as social differentiation, 30 p.

Research joint ventures and price collusion: Joint analysis of the impact of R\&D subsidies and antitrust fines, $30 \mathrm{p}$.

Strategic choice analysis by expert panels for migration impact assessment, 41

p.

The market value of listed heritage: An urban economic application of spatial hedonic pricing, $24 \mathrm{p}$.

Socio-economic impacts of heterogeneity among foreign migrants: Research and policy challenges, $17 \mathrm{p}$. 
2011-29

Masood Gheasi Peter Nijkamp

2011-30

Karima Kourtit

Peter Nijkamp

Eveline van Leeuwen

Frank Bruinsma

2011-31 Cathy Macharis

Peter Nijkamp

2011-32 John Steenbruggen

Maria Teresa

Borzacchiello

Peter Nijkamp

Henk Scholten

2011-33

John Steenbruggen

Peter Nijkamp

Jan M. Smits

Michel Grothe

2011-34 Tüzin Baycan

Peter Nijkamp

2011-35 Adele Finco

Deborah Bentivoglio

Peter Nijkamp

2011-36 Eric de Noronha Vaz

Pedro Cabral

Mário Caetano

Peter Nijkamp

Marco Paínho

2011-37 Maria Giaoutzi

Anastasia Stratigea

Eveline van Leeuwen

Peter Nijkamp

2011-38 Peter Nijkamp

Patricia van Hemert

2011-39 Patricia van Hemert

Enno Masurel

Peter Nijkamp

2011-40 Eric de Noronha Vaz

Marco Painho

Peter Nijkamp

2011-41 Karima Kourtit

Peter Nijkamp

Steef Lowik

Frans van Vught

Paul Vulto
Migration, tourism and international trade: Evidence from the UK, 8 p.

Evaluation of cyber-tools in cultural tourism, $24 \mathrm{p}$.

Possible bias in multi-actor multi-criteria transportation evaluation: Issues and solutions, $16 \mathrm{p}$.

The use of GSM data for transport safety management: An exploratory review, $29 \mathrm{p}$.

Traffic incident management: A common operational picture to support situational awareness of sustainable mobility, $36 \mathrm{p}$.

Students' interest in an entrepreneurial career in a multicultural society, $25 \mathrm{p}$.

Integrated evaluation of biofuel production options in agriculture: An

exploration of sustainable policy scenarios, $16 \mathrm{p}$.

Urban heritage endangerment at the interface of future cities and past heritage:

A spatial vulnerability assessment, $25 \mathrm{p}$.

Scenario analysis in foresight: AG2020, 23 p.

Knowledge infrastructure and regional growth, $12 \mathrm{p}$.

The role of knowledge sources of SME's for innovation perception and regional innovation policy, $27 \mathrm{p}$.

Impacts of environmental law and regulations on agricultural land-use change and urban pressure: The Algarve case, $18 \mathrm{p}$.

From islands of innovation to creative hotspots, $26 \mathrm{p}$. 
2011-42

Alina Todiras

Peter Nijkamp

Saidas Rafijevas

2011-43 Eric de Noronha Vaz

Mário Caetano

Peter Nijkamp

2011-44 Andrea Caragliu

Chiara Del Bo

Peter Nijkamp

2011-45 Patrizia Lombardi

Silvia Giordano

Andrea Caragliu

Chiara Del Bo

Mark Deakin

Peter Nijkamp

Karima Kourtit

2011-46 Jessie Bakens

Peter Nijkamp

2011-47 Irene Casas

Maria Teresa

Borzacchiello

Biagio Ciuffo

Peter Nijkamp

2011-48 Christian Bogmans

2011-49 Karim Abbas

Bernd Heidergott

Djamil Aïssani

2011-50 Eric Koomen

2012-1 Aliye Ahu Gülümser

Tüzin Baycan Levent

Peter Nijkamp

Jacques Poot

2012

2012-2 Joao Romao

Bart Neuts

Peter Nijkamp

Eveline van Leeuwen

2012-3 Vincent A.C. van den Berg

2012-4 Vasco Diogo

Eric Koomen

Floor van der Hilst
Innovative marketing strategies for national industrial flagships: Brand repositioning for accessing upscale markets, $27 \mathrm{p}$.

A multi-level spatial urban pressure analysis of the Giza Pyramid Plateau in Egypt, 18 p.

A map of human capital in European cities, $36 \mathrm{p}$.

An advanced triple-helix network model for smart cities performance, $22 \mathrm{p}$.

Migrant heterogeneity and urban development: A conceptual analysis, $17 \mathrm{p}$.

Short and long term effects of sustainable mobility policy: An exploratory case study, $20 \mathrm{p}$.

Can globalization outweigh free-riding? $27 \mathrm{p}$.

A Taylor series expansion approach to the functional approximation of finite queues, $26 \mathrm{p}$.

Indicators of rural vitality. A GIS-based analysis of socio-economic development of the rural Netherlands, $17 \mathrm{p}$.

The role of local and newcomer entrepreneurs in rural development: A comparative meta-analytic study, $39 \mathrm{p}$.

Urban tourist complexes as Multi-product companies: Market segmentation and product differentiation in Amsterdam, $18 \mathrm{p}$.

Step tolling with price sensitive demand: Why more steps in the toll makes the consumer better off, $20 \mathrm{p}$.

Second generation biofuel production in the Netherlands. A spatially-explicit exploration of the economic viability of a perennial biofuel crop, $12 \mathrm{p}$. 
2012-5 Thijs Dekker

Paul Koster

Roy Brouwer

2012-6 Daniel Arribas

Karima Kourtit

Peter Nijkamp

2012-7 Karima Kourtit

Peter Nijkamp

Frans van Vught

Paul Vulto

2012-8 Mediha Sahin

Tüzin Baycan

Peter Nijkamp

2012-9 Peter Nijkamp

Jacques Poot

2012-10 Tibert Verhagen

Anniek Nauta

Frans Feldberg

2013

2013-1 Tüzin Baycan

Peter Nijkamp

2013-2 Haralambie Leahu

2013-3 Tibert Verhagen

Charlotte Vonkeman

Frans Feldberg

Plon Verhagen

2013-4 Aliye Ahu Akgün

Eveline van Leeuwen

Peter Nijkamp

2013-5 John Steenbruggen

Peter Nijkamp

Maarten van der Vlist

2013-6 Jorge Ridderstaat

Robertico Croes

Peter Nijkamp

2013-7 Masood Gheasi

Peter Nijkamp

Piet Rietveld

2013-8 Mediha Sahin

Peter Nijkamp

Soushi Suzuki
Changing with the tide: Semi-parametric estimation of preference dynamics, 50 p.

Benchmarking of world cities through self-organizing maps, $22 \mathrm{p}$.

Supernova stars in knowledge-based regions, $24 \mathrm{p}$.

The economic importance of migrant entrepreneurship: An application of data envelopment analysis in the Netherlands, $16 \mathrm{p}$.

Migration impact assessment: A state of the art, $48 \mathrm{p}$.

Negative online word-of-mouth: Behavioral indicator or emotional release? 29 p.

The migration development nexus: New perspectives and challenges, $22 \mathrm{p}$.

European Options Sensitivities via Monte Carlo Techniques, 28 p.

Making online products more tangible and likeable: The role of local presence as product presentation mechanism, $44 \mathrm{p}$.

A Multi-actor multi-criteria scenario analysis of regional sustainable resource policy, $24 \mathrm{p}$.

Urban traffic incident management in a digital society. An actor-network approach in information technology use in urban Europe, $25 \mathrm{p}$.

The force field of tourism, $19 \mathrm{p}$.

Unknown diversity: A study on undocumented migrant workers in the Dutch household sector, $17 \mathrm{p}$.

Survival of the fittest among migrant entrepreneurs. A study on differences in the efficiency performance of migrant entrepreneurs in Amsterdam by means of data envelopment analysis, $25 \mathrm{p}$. 
2013-9 Kostas Bithas Peter Nijkamp

2013-10 Madalina-Stefania

Dirzu

Peter Nijkamp

2013-11 Eric de Noronha Vaz Agnieszka Walczynska Peter Nijkamp

2013-12 João Romão

Eveline van Leeuwen

Bart Neuts

Peter Nijkamp

2013-13 Jorge Ridderstaat

Marck Oduber

Robertico Croes

Peter Nijkamp

Pim Martens

2013-14 Emmanouil Tranos

Peter Nijkamp

2013-15 Masood Gheasi

Peter Nijkamp

Piet Rietveld

2013-16 Serenella Sala

Biagio Ciuffo

Peter Nijkamp

2013-17 Eveline van Leeuwen

Peter Nijkamp

Aliye Ahu Akgün

Masood Gheasi

2013-18 Aliye Ahu Akgün

Eveline van Leeuwen

Peter Nijkamp

2013-19 Peter Nijkamp

2013-20 Aliye Ahu Akgün

Eveline van Leeuwen

Peter Nijkamp

2013-21 Vicky Katsoni

Maria Giaoutzi

Peter Nijkamp

2013-22 Jorge Ridderstaat

Robertico Croes

Peter Nijkamp
Biological integrity as a prerequisite for sustainable development: A bioeconomic perspective, $24 \mathrm{p}$.

The dynamics of agglomeration processes and their contribution to regional development across the EU, 19 p.

Regional challenges in tourist wetland systems: An integrated approach to the Ria Formosa area, 17 p.

Tourist loyalty and urban e-services: A comparison of behavioural impacts in Leipzig and Amsterdam, 19 p.

Impacts of seasonal patterns of climate on recurrent fluctuations in tourism demand. Evidence from Aruba, $34 \mathrm{p}$.

Urban and regional analysis and the digital revolution: Challenges and opportunities, $16 \mathrm{p}$.

International financial transfer by foreign labour: An analysis of remittances from informal migrants, $11 \mathrm{p}$.

A meta-framework for sustainability assessment, $24 \mathrm{p}$.

Foresights, scenarios and sustainable development - a pluriformity perspective, $19 \mathrm{p}$.

Analytical support tools for sustainable futures, $19 \mathrm{p}$.

Migration impact assessment: A review of evidence-based findings, 29 p.

Sustainability science as a basis for policy evaluation, $16 \mathrm{p}$.

Market segmentation in tourism - An operational assessment framework, 28 p.

Tourism development, quality of life and exogenous shocks. A systemic analysis framework, $26 \mathrm{p}$. 
2013-23

Feng Xu

Nan Xiang

Shanshan Wang

Peter Nijkamp

Yoshiro Higano

2013-24 John Steenbruggen

Peter Nijkamp

Jan M. Smits

Ghaitrie Mohabir

2013-25 Patricia van Hemert

Peter Nijkamp

Enno Masurel

2013-26

Patricia van Hemert

Peter Nijkamp

Enno Masurel

2013-27 Mediha Sahin

Alina Todiras

Peter Nijkamp

2013-28 Tüzin Baycan

Mediha Sahin

Peter Nijkamp

2013-29 Eric Vaz

Teresa de Noronha

Vaz

Peter Nijkamp

2013-30 Eric Vaz

Marco Painho

Peter Nijkamp

2013-31 Yueting Guo

Hengwei Wang

Peter Nijkamp

Jiangang XU

2013-32 Maurice de Kleijn

Niels van Manen

Jan Kolen

Henk Scholten

2013-33 Erik van der Zee

Henk Scholten

2013-34 Mehmet Güney Celbiş

Peter Nijkamp

Jacques Poot

2013-35 Marco Modica

Aura Reggiani

Peter Nijkamp
Dynamic simulation of China's carbon emission reduction potential by 2020,12 p.

Traffic incident and disaster management in the Netherlands: Challenges and obstacles in information sharing, $30 \mathrm{p}$.

From innovation to commercialization through networks and agglomerations: Analysis of sources of innovation, innovation capabilities and performance of Dutch SMEs, $24 \mathrm{p}$.

How do SMEs learn in a systems-of-innovation context? The role of sources of innovation and absorptive capacity on the innovation performance of Dutch SMEs, $27 \mathrm{p}$.

Colourful entrepreneurship in Dutch cities: A review and analysis of business performance, $25 \mathrm{p}$.

The urban growth potential of second-generation migrant entrepreneurs. A sectoral study on Amsterdam, $31 \mathrm{p}$.

The architecture of firms' innovative behaviors, $23 \mathrm{p}$.

Linking agricultural policies with decision making: A spatial approach, $21 \mathrm{p}$.

Space-time changes in interdependent urban-environmental systems: A policy study on the Huai River Basin in China, 20 p.

User-centric SDI framework applied to historical and heritage European landscape research, $31 \mathrm{p}$.

Application of geographical concepts and spatial technology to the Internet of Things, $35 \mathrm{p}$.

The lucrative impact of trade-related infrastructure: Meta-Analytic Evidence, 45 p.

Are Gibrat and Zipf Monozygotic or Heterozygotic Twins? A Comparative Analysis of Means and Variances in Complex Urban Systems, 34 p. 
2013-36

Bernd Heidergott

Haralambie Leahu

Warren Volk-

Makarewicz

2013-37 Peter Nijkamp

Waldemar Ratajczak

2013-38 Karima Kourtit

Peter Nijkamp

Eveline van Leeuwen

\section{4}

2014-1 John Steenbruggen

Emmanouil Tranos

Peter Nijkamp

2014-2 John Steenbruggen

2015

2015-1 Maurice de Kleijn

Rens de Hond

Oscar Martinez-Rubi

Pjotr Svetachov

2015-2 Gilberto Mahumane

Peter Mulder

2015-3 Karim Abbas

Joost Berkhout

Bernd Heidergott

2015-4 Nahom Ghebrihiwet

Evgenia Motchenkova

2015-5 Yannis Katsoulacos

Evgenia Motchenkova

David Ulph

2015-6 John Steenbruggen

Emmanouil Tranos

Piet Rietveld ${ }^{\dagger}$

2015-7 Gilberto Mahumane

Peter Mulder
A Smoothed Perturbation Analysis Approach to Parisian Options, 14 p.

The Spatial Economy - A Holistic Perspective, 14 p.

New Entrepreneurship in Urban Diasporas in our Modern World, 22 p.

Data from mobile phone operators: A tool for smarter cities? $22 \mathrm{p}$.

Tourism geography: Emerging trends and initiatives to support tourism in Morocco, $29 \mathrm{p}$.

A 3D Geographic Information System for 'Mapping the Via Appia', 11 p.

Introducing MOZLEAP: an integrated long-run scenario model of the emerging energy sector of Mozambique, $35 \mathrm{p}$.

A Critical Account of Perturbation Analysis of Markovian Systems, 28 p.

Technology Transfer by Foreign Multinationals, Local Investment, and FDI Policy, $31 \mathrm{p}$.

Penalizing Cartels: The Case for Basing Penalties on Price Overcharge, 43 p.

Can Motorway Traffic Incidents be detected by Mobile Phone Usage Data? 21 p.

Mozambique Energy Outlook, 2015-2030. Data, Scenarios and Policy Implications. $47 \mathrm{p}$. 